IZA DP No. 9731

Identity Conflict with Cross-Border Spillovers

Dripto Bakshi

Indraneel Dasgupta

February 2016 


\title{
Identity Conflict with Cross-Border Spillovers
}

\author{
Dripto Bakshi \\ Indian Statistical Institute \\ Indraneel Dasgupta \\ Indian Statistical Institute \\ and IZA
Discussion Paper No. 9731
February 2016 \\ IZA \\ P.O. Box 7240 \\ 53072 Bonn \\ Germany \\ Phone: +49-228-3894-0 \\ Fax: +49-228-3894-180 \\ E-mail: iza@iza.org
}

\begin{abstract}
Any opinions expressed here are those of the author(s) and not those of IZA. Research published in this series may include views on policy, but the institute itself takes no institutional policy positions. The IZA research network is committed to the IZA Guiding Principles of Research Integrity.

The Institute for the Study of Labor (IZA) in Bonn is a local and virtual international research center and a place of communication between science, politics and business. IZA is an independent nonprofit organization supported by Deutsche Post Foundation. The center is associated with the University of Bonn and offers a stimulating research environment through its international network, workshops and conferences, data service, project support, research visits and doctoral program. IZA engages in (i) original and internationally competitive research in all fields of labor economics, (ii) development of policy concepts, and (iii) dissemination of research results and concepts to the interested public.
\end{abstract}

IZA Discussion Papers often represent preliminary work and are circulated to encourage discussion. Citation of such a paper should account for its provisional character. A revised version may be available directly from the author. 
IZA Discussion Paper No. 9731

February 2016

\section{ABSTRACT}

\section{Identity Conflict with Cross-Border Spillovers*}

We model simultaneous inter and within identity-group conflict in two territories connected by cross-territorial spill-overs. Within each territory, two groups contest the division of a groupspecific public good, and all members contest the division of group income. Each group has a cross-border affiliate. Greater success (share) of its affiliate 'spills over' into higher efficiency of a group in inter-group conflict. We find that inter-group and total conflict move together within a territory, while within-group conflict and output move in the opposite direction. A unilateral increase in cross-border spill-over reduces inter-group conflict in the source territory but increases it in the destination; an equi-proportionate bilateral increase affects conflict in a non-monotone manner. Population increase in a territory, a larger minority, weaker property rights, higher relative labour productivity of the majority, may all increase inter-group conflict in the other territory. Community-neutral growth in labour productivity within a territory reduces inter-group conflict therein.

JEL Classification: D72, D74, O10, O20

Keywords: ethnic conflict, identity, simultaneous between and within group contest, cross-border spillover, globalization, ethnic polarization, community-biased growth

Corresponding author:

Indraneel Dasgupta

Economic Research Unit

Indian Statistical Institute

203 Barrackpore Trunk Road

Kolkata 700108, West Bengal

India

E-mail: indraneel@isical.ac.in

* We thank Soumyanetra Munshi for helpful discussions. 


\section{Introduction}

In recent decades, conflicts between 'ethnic' communities, i.e. groups divided along non-class identity dimensions such as race, language, and, in particular, religion, have attained increasing salience in many countries. In response to this, a large analytical and empirical literature has developed in political science and political economics that seeks to explicate various aspects of this phenomenon. This literature however largely focuses on the internal drivers of ethnic conflict within a society. ${ }^{1}$ What has received much less attention is how 'foreign', or extra-territorial, influences affect and condition such conflict. ${ }^{2}$ The purpose of this paper is to shed analytical light on this neglected issue.

The same, or closely related, rival ethnic groups are often spread over multiple countries. Shias and Sunnis spread over all countries in the Middle East, Hutus and Tutsis over Rwanda and Burundi, Hindus and Muslims over India and Bangladesh, constitute examples. A conceptually similar situation obtains when the same religious group constitutes the overwhelming majority in two different territories, but is cleaved between antagonistic theocratic and secularizing political tendencies (as for example obtains among Hindus in India and Nepal, or among Muslims in Turkey, Algeria, Libya, Tunisia and Morocco). Yet another related phenomenon is a single ethnic group spread over multiple countries, but facing different ethnic groups in different countries (such as the Pashtuns across Pakistan and Afghanistan, the Kurds across Turkey, Iraq, Syria and Iran, the Russians across the successor countries of the former Soviet Union, and the Tamils across India and Sri Lanka).

In these cases, the balance of power between two antagonistic groups within a territory is often likely to 'spill-over' into another territory; i.e., to impact inter-group conflict in the latter. The spill-over effect of Shia-Sunni conflict in Iraq on Syria and Lebanon, and vice versa, in the context of the recent rise of the Islamic State of Iraq and the Levant, is a well-documented example, as is the spill-over effect of the war in Afghanistan on Pakistan. Hindu-Muslim conflicts in India and Bangladesh show similar spill-overs. Given extra-territorial solidarity or identity of interest on the part of antagonistic domestic groups, the balance of power between them may be expected to be reflected in the 'foreign policy bias' of a country (say 1), as partisan financial, military, logistical, organisational and propaganda support to favoured groups in another country (say 2), both official and private. Greater external support is likely to find practical reflection in greater cross-border access to safe houses, sanctuaries, strategically important roads, mountains, pre-existing stocks of military hardware (especially aircraft, tanks and heavy artillery) that cannot be easily acquired from market

${ }^{1}$ Bakshi and Dasgupta (2015), Caselli and Coleman (2013), Dasgupta and Kanbur (2007, 2005b), and Esteban and Ray $(2011,2008)$ are recent theoretical contributions in economics. Easterly (2001) examines the role of institutions in ethnic conflict. Hoeffler (2012) surveys the literature on civil wars. Davidson (2008), Varshney (2008, 2002), van Klinken (2007) and Wilkinson (2005) are recent studies in political science on ethnic riots.

2 Exceptions are Gleditsch (2007), who finds the number of ethnic groups that span national borders to be positively correlated with the onset of civil war; and Collier and Hoeffler (2004), who find that countries with large diasporas in the US are more likely to experience civil war. 
purchase in the short run, military and political trainers, cross-border bases and training camps, diplomatic, media and propaganda support, international lobbying, etc. These diverse forms of external support from 1 to the group (say A) favoured by 1 in 2 can be viewed as complementary to A's own mobilization of resources for conflict with other groups in 2: they augment the efficiency of such mobilization and thereby affect the conflict outcome in 2. By the same token, however, the latter in turn impacts on group conflict in 1. Thus, group conflicts are mutually determined in the presence of cross-territorial identification among contending groups. ${ }^{3}$ Furthermore, since components of individual groups have conflicting as well as common interests, such mutual conditioning would involve the determination of intra-group conflict within the broader contending formations as well.

The following questions then suggest themselves. First, how does an increase in the ability, of the balance of power within one country to affect group conflict in another (i.e. in the strength of cross-border spill-overs), affect conflict and inter-group distribution in either country? Since economic growth, greater commodity, capital and labour market integration, more extensive and porous common borders, all can be expected to expand such ability, the answer sheds light on the connection between economic growth, market openness and domestic conflict. Second, how do changes in demographic and economic fundamentals of a country, such as population size, population distribution between contending groups, their relative labour productivity and the strength of property rights protection, affect conflict in another country? The answers provide important insights into the workings of external drivers of domestic conflict. This paper seeks to address these questions.

The revival of ethnic (especially religious) identities in recent decades, and the increasing salience of mass political conflict, both among rival ethnic identities and between religious and secular identities, over extra-economic aspects of life, lead us to focus on inter-group conflict over items of group-wide non-excludable benefit ('culture/religion') rather than private consumption ('income'). Building on Dasgupta and Kanbur (2011, 2007, 2005a), we visualize identity groups within a territory as held together by the common consumption of certain forms of group-specific public goods, which do not yield monetary benefits, but are intrinsically valuable. In accord with Esteban and Ray (2011, 2008), we model such collective consumption as generating conflict between groups. A group finds its collective identity in religious shrines, monuments to its heroes, memory rituals of past victories and defeats, the naming of parks, streets, bridges, towns and universities after its revered members, public gatherings to perform collective religious rituals, state observance of occasions important to its perceived collective history, etc. Core values and norms identified with

\footnotetext{
${ }^{3}$ Relations between India and Bangladesh illustrate the point. India sheltered the Buddhist tribal group Shanti Bahini fighting an insurgency against the Bangladeshi government, for autonomy and against Muslim settlement in the Chittagong Hill Tracts, from the mid-1970s till 1997. Successive military and Islamist-leaning regimes in Bangladesh retaliated by providing shelter and support to minority ethnic insurgent groups in India's north-east. See Riaz (2008, chap. 4). A clamp-down on their activities in Bangladesh occurred only when the secular Awami League came to power with support from the Hindu and Buddhist minorities.
} 
particular ethno-religious groups typically guide the responses of members to laws regulating private behaviour of individuals, especially in matters of marriage, sexual preference and behaviour, divorce, abortion, inheritance ('personal' law), dietary habits (as in the consumption of halal meat, beef, pork and alcohol), dress codes (as in the wearing of Sikh turbans, or Islamic veils) and religious commentary ('blasphemy'). When a society consists of multiple ethnic groups, overt public displays of its exclusive physical symbols or society-wide imposition of its exclusive behavioural norms by any one group is likely to generate conflicts. These may involve attempts by groups to lobby/bribe authorities to act in their favour, or direct action. ${ }^{4}$ Such conflicts engage real resources, but the gains are directly psychic, i.e. non-material. We demarcate them as occurring in the sphere of collective symbolic consumption, rather than in that of private material consumption. Identical considerations hold for conflicts between groups driven by theocratic and secularizing ideologies.

Societies with sharp ethnic divides also exhibit locational segregation: neighbourhoods are divided along ethnic lines, enterprises feature ethnic homogeneity in employee recruitment, and specific ethnic groups often cluster in particular occupations and market segments. Albeit to a lesser extent, this also holds for the secular-theocratic identity divide: secularizing or anti-clerical identities are often more concentrated in cities, while religious or theocratic identities are more firmly rooted in the rural areas. Consequently, decentralized distributive conflicts within an identity group over expropriation of divisible consumption ('income') often acquire a greater immediacy and salience, compared to such conflicts across groups. ${ }^{5}$ We abstract from the latter to focus on the former.

We model mutual determination of simultaneous inter and within group conflict in two territories (societies) connected by cross-territorial spill-overs. Within each territory, two groups contest one another, in Tullock (1980) fashion, over sharing of one unit of a composite good ('state religion/culture' for intuitive focus), interpreted as the composite of extra-economic behavioural rules and items of reverence, including norms of extra-territorial identification and solidarity, enforced on the entire society. ${ }^{6}$ Possession of this composite good leads to non-rival and non-excludable

\footnotetext{
${ }^{4}$ An example of the first is the 2009 referendum in Switzerland, whereby a constitutional amendment banning new mosque minarets was approved by $57.5 \%$. Direct action may be legal and peaceful or illegal and violent, as when it involves the mobilization of activists' to control or physically destroy places of worship or monuments belonging to other communities, or to terrorize other communities to force them to desist from observing certain practices or rituals. Conflicts over the construction and ownership of religious structures, as between Hindus and Muslims in India, Bangladesh and Pakistan or between Muslims and Jews in Jerusalem, attacks on writers and cartoonists on grounds of blasphemy or the routine bombings of Shia religious celebrations and Sufi shrines by Sunni extremists in Iraq and Pakistan, all constitute common examples of violent direct action.
}

${ }^{5}$ For example, during 1976-2005, 94\% of black murder victims in the US were killed by black offenders, while 86\% of white victims were killed by white offenders (http://www.thedailybeast.com/articles/2013/07/15/thetrayvon-martin-killing-and-the-myth-of-black-on-black-crime.html). .

6 An intuitive illustration is the campaign by the French Front National before the regional elections of December 2015. The party's leader Marine Le Pen campaigned on issues of Islam's place in France and national identity, telling a rally in Corsica: "To merit French nationality, you have to speak French, eat French 
consumption benefits within a group, but is mutually exclusive between groups. ${ }^{7}$ Within each territory, all members (equivalently, factions) of each group also engage in Tullock contestation over the division of total group resources available for rival consumption (group 'income'). Each member of society is endowed with one unit of effort, which she allocates among inter-group conflict, within group contestation, and productive (i.e. income-generating) activity. Each group in a territory has an affiliate in the other territory, interpreted alternatively as ethnic kin, or opponent of a common ethnic enemy. Success in inter-group conflict within a territory depends on both internal effort mobilization and external support. The extent to which a given amount of inter-group conflict effort by a group (say A) in a territory gets translated into conflict success (share) depends positively on the success (share) of A's affiliate in the other territory. Thus, (i) domestic balance of power between groups within a territory gets reflected in differential support to external groups from this territory (its 'foreign policy bias'), and (ii) external support complements domestic mobilization in inter-group conflict within a territory. All resource allocation, in either territory, happens simultaneously, so that conflict, production and distribution in the two territories are mutually determined. ${ }^{8}$

We find that inter-group and total conflict move together within a territory, while withingroup conflict and social output move in the opposite direction. Suppose a group, B, has a cost disadvantage in territory 2 , which is at least proportionately compensated by a cost advantage for B's affiliate in territory 1 . Suppose further that B is the dominated (less successful) party in the intergroup conflict in 2 , though its affiliate is dominant in 1 . Then, a unilateral increase in the ability of the inter-group balance of power in either territory to influence conflict in the other territory, i.e., in its 'spill-over elasticity' (say, due to faster economic growth in the former, or because of a unilateral

and live French.” The party's MP and rising star Marion Maréchal-Le Pen claimed Muslims could not be French unless they "yield to the manners and our way of life" inherited from France's Christian traditions. (Chrisafis, 2015). A precedent is French policy in colonial Algeria, administered as an integral part of France. The decree of 1865 by Napoleon III made full French citizenship for Algerian Muslims contingent on their acceptance of the complete jurisdiction of the French legal code, including laws affecting marriage and inheritance, and rejection of the authority of the religious courts. Over the next century, fewer than 3,000 Algerian Muslims took up French citizenship. See Brett (1988) for a discussion.

${ }^{7}$ Contests over public goods were introduced by Katz et al. (1990).

8 Recent contributions on simultaneous between and within group contests are Choi et al. (2015), Dasgupta (2009) and Munster (2007). These model conflicts solely over private goods, and cannot therefore address the non-pecuniary identity conflicts that we highlight. Furthermore, they feature a single site of inter-group conflict. In contrast to the literature on conflict in multiple battlefields (see Kovenock and Roberson (2012) for a recent survey), the same agents do not confront one another in multiple battlefields (territories) in our model. Our agents do not maximize any aggregation of the pay-offs in the two territories. They only maximize their pay-offs generated in their own territory: the consequent outcome in one affects that in the other as a parametric change in the conflict environment. This captures the idea that while identity groups may feel tied to affiliates across borders because of certain shared features, cross-border differences in other features are sufficiently salient to preclude coordination to the extent that merits modelling in terms of a common aggregative group objective function across borders. Instead, we pursue the idea that decentralized groups pursue their objectives within their own territory, but greater success in doing so by a group advantages its cross-border affiliate. Partisan cross-border impact, and success in domestic inter-group conflict, are thus joint products in our model. 
relaxation of import restrictions, restrictions on private aid and capital flows and immigration controls in the latter) reduces both external and total conflict in the former territory but 'exports' them to (increases them in) the latter. Thus, greater unilateral economic integration by a country with another country may increase conflict and reduce output in the integrating country. Greater spill-over from a territory benefits both the dominant group in that territory, and its affiliate in the other. An equiproportionate increase in spill-over elasticities (say, due to similar economic growth in the two territories, or an expansion in bilateral trade and labour market integration), intuitively interpreted as greater bilateral economic integration, affects group conflict in a non-monotone fashion within each territory. This initially increases group conflict in both territories; at intermediate levels it moves conflict in opposite directions across territories; at already high levels of integration it reduces conflict in both territories. It may affect the welfare of a group and its affiliate in opposite ways.

We also investigate how changes in demographic and economic fundamentals within a territory affect conflict in another territory, explicitly incorporating a majority-minority divide. We assume that a group constitutes the minority in a territory if and only if its affiliate is the minority in the other territory. We find that population increase in a territory that does not reduce the minority's share, an enlargement of the minority that does not reduce total population, weaker property rights protection across groups, and an increase in the relative labour productivity of the majority, all increase both inter-group and aggregate conflict in the other territory, when the minority is dominated in both territories. However, when the minority dominates in one, but is dominated in another, such changes in one territory may increase or decrease inter-group and aggregate conflict in the other territory, depending on which territory the changes occur in. These changes nonetheless always make the minority in the other territory better off, while making the majority therein worse off. Community neutral growth in labour productivity within a territory reduces both inter-group and aggregate conflict, but increases intra-group conflict and output within both groups in that territory.

Section 2 sets up the model, in the context of a single territory. Section 3 embeds crossterritorial spill-overs and examines how changes therein affect conflict and distribution. Section 4 discusses the impact of changes, in demographic and economic variables within a territory, on conflict and distribution in the other territory. Section 5 illustrates some possible applications of our findings and offers concluding comments. Detailed proofs of propositions are relegated to an appendix.

\section{The model}

Consider a scenario where two identity communities, A and B, are spread across two territorial-cum political units (say, two countries or two provinces of the same country), 1 and 2. Cross-territorial identification within each community obtains due to the shared possession of some identity marker (religion, race, caste or language): territorial fragments of a community ('groups') affiliate with one another in this sense. For example, A and B may refer to different religions, so that membership of community $g \in\{A, B\}$ is defined by the common experience of practising religion $g$ irrespective of 
location: group $g$ in 1 and group $g$ in 2 are affiliates. ${ }^{9}$ Given any $g \in\{A, B\}$, we shall denote the other community by $-g$; given any territory $j \in\{1,2\}$, we shall denote the other territory by $-j$. Thus, there are four groups, each defined formally by its combination of community identity and location; i.e., by a pair $\langle g, j\rangle \in C \equiv\{A, B\} \times\{1,2\}$. Within each territory, the two constituent identity groups simultaneously engage in 'external', or inter-group, conflict over the sharing of some group-specific public good, whose benefits are non-excludable within a group, but mutually exclusive across groups, and 'internal' conflict over the sharing of excludable resources ('income') among group members. Furthermore, such conflict processes operate simultaneously in the two territories. The outcome of the external conflict within each territory influences, and is influenced by, the outcome of the external conflict in the other territory: conflict thus has cross-territory spill-over effects.

We first model the conflict process within each territory in isolation, postponing the discussion of cross-territory spill-overs to Section 3. In each territory $j \in\{1,2\}$, there are $n_{j}$ individuals (or, equivalently, factions) partitioned into the two communities, A and B, of size $n_{A j}, n_{B j}$, respectively. Each individual (or faction) is endowed with one unit of effort. Individual $i \in$ $\left\{1,2, \ldots, n_{g j}\right\}$ in group $\langle g, j\rangle$ chooses productive effort $e_{i g, j}$, intra-group conflict effort $x_{i g, j}$, and intergroup conflict effort $y_{i g, j}$, subject to the non-negativity constraints $e_{i g, j} \geq 0, x_{i g, j} \geq 0, y_{i g, j} \geq 0$, and the budget constraint $\left[e_{i g, j}+x_{i g, j}+y_{i g, j}=1\right]$. Total intra-group conflict effort for group $\langle g, j\rangle$ is $x_{g j} \equiv \sum_{i=1}^{n_{g j}} x_{i g, j}$, while total inter-group conflict effort allocated by that group is $y_{g j} \equiv \sum_{i=1}^{n_{g j}} y_{i g, j}$. There exists one unit of some composite group-specific public good in each territory, whose division is contested over by the two groups in that territory, with $\langle g, j\rangle$ getting the share $p_{g j} ; p_{A j}+p_{B j}=1$. As discussed in Section 1, the public good may intuitively be interpreted as the composite of extraeconomic behavioural rules and items of reverence, including norms of extra-territorial identification and solidarity, enforced on the entire society. A higher share for a group implies that the society as a whole is forced to adopt or correspond to that group's values and norms to a greater extent. The valuation of the group-specific public good by members of $\langle g, j\rangle$ is $T_{g j}$. Thus, the monetary equivalent of the benefit to each individual member of $\langle g, j\rangle$ from the group as a whole receiving the share $p_{g j}$ of the public good is $p_{g j} T_{g j}$. Recall that we wish to model a situation of residential and economic segregation, where different groups are concentrated in different areas (regions, districts or ethnic neighbourhoods). Accordingly, we assume that group $\langle g, j\rangle$ is endowed with some immovable and indivisible productive asset $L_{g j}$ (intuitively identified with stock of human capital, infrastructure including transport and communication network, coastline, climate or land productivity); this asset is complementary to labour. For an individual member, $i$, of group $\langle g, j\rangle$, output is thus given by:

$$
q_{i g, j}=L_{g j}\left(1-x_{i g, j}-y_{i g, j}\right) .
$$

9 As discussed in Section 1, A and B may also refer to secularizing/anti-clerical and theocratic political tendencies within the same religious community spread over two territories. 
Group output is given by the sum of individual outputs:

$$
q_{g j}=\sum_{i=1}^{n_{g j}} q_{i g, j}=L_{g j}\left(n_{g j}-x_{g j}-y_{g j}\right) .
$$

An individual member of the group can costlessly retain $\left(1-\mu_{g j}\right) \in[0,1)$ proportion of her output. The consequent pool of expropriable income/output, $\mu_{g j} q_{g j}$, is divided among the group members as the outcome of a process of decentralized intra-community distributive conflict, defined by the standard (Tullock, 1980) contest success function. The parameter $\mu_{g j}$ thus measures the extent to which individual property rights are protected within the group: a higher value of this parameter implies weaker protection of private property rights. This formulation permits the possibility that different groups protect private property rights of group members differentially. One group may provide stronger protection because its internal governance institutions (broadly interpreted to include the church, caste/clan/village councils etc.) are better at instilling property-preserving social norms within the group and/or censuring infringements. Thus, the net income of an individual in $\langle g, j\rangle$ is:

$$
\begin{aligned}
r_{i g, j}= & \mu_{g j}\left(\frac{x_{i g, j}}{x_{g j}}\right) q_{g j}+\left(1-\mu_{g j}\right) L_{g j}\left[1-x_{i g, j}-y_{i g, j}\right] \text { if } x_{g j} \equiv \sum_{i=1}^{n_{g j}} x_{i g, j}>0 ; \\
= & \mu_{g j}\left(\frac{1}{n_{g j}}\right) q_{g j}+\left(1-\mu_{g j}\right) L_{g j}\left[1-x_{i g, j}-y_{i g, j}\right] \text { otherwise. }
\end{aligned}
$$

A group member's aggregate utility, or pay-off, is given by:

$$
u_{i g, j}=p_{g j} T_{g j}+r_{i g, j} \text {. }
$$

The outcome of the inter-group contest over sharing of the group-specific public good is defined by a Tullock contest success function, so that group $\langle A, j\rangle$ gets the fraction:

$$
\begin{aligned}
& p_{A j}=\frac{y_{A j}}{y_{A j}+z_{j} y_{B j}} \text { if } y_{j} \equiv y_{A j}+y_{B j}>0 ; \\
& =\frac{1}{1+z_{j}} \text {, otherwise; }
\end{aligned}
$$

where $z_{j}>0$ is a parameter measuring the relative efficiency of B's conflict effort in inter-community conflict in territory $j$. All individuals in both territories simultaneously choose their inter and intracommunity conflict effort allocations to maximize their utility function (3), subject to (1), (2), (4) and the individual budget constraint. It can be checked that the utility function (3) is strictly quasiconcave in $\left(x_{i g, j}, y_{i g, j}\right)$. Hence, a unique solution exists to the maximization problem of the individual, given the conflict contributions by the rest of the society and the parameters $\mu_{j}, z_{j}$.

Suppose an interior equilibrium exists. Then, dropping the territory subscript $j$ for notational simplicity, the FOCs yield:

$$
\begin{aligned}
& \mu_{g}\left[\frac{x_{g}-x_{i g}}{x_{g}{ }^{2}}\right]=\frac{\left[\mu_{g}\left(\frac{x_{i g}}{x_{g}}\right)+\left(1-\mu_{g}\right)\right]}{\left(n_{g}-x_{g}-y_{g}\right)} ; \\
& T_{g} \frac{\partial p_{g}}{\partial y_{i g}}=\left[\mu_{g}\left(\frac{x_{i g}}{x_{g}}\right)+\left(1-\mu_{g}\right)\right] L_{g} .
\end{aligned}
$$

Summing over all members of $g$ in the territory, we get, from (5): 


$$
\left[\frac{n_{g}-1}{x_{g}}\right]=\frac{\mu_{g}+\left(1-\mu_{g}\right) n_{g}}{\mu_{g}\left(n_{g}-x_{g}-y_{g}\right)} .
$$

Hence,

$$
x_{g}=\frac{\mu_{g}\left(n_{g}-1\right)}{n_{g}}\left(n_{g}-y_{g}\right)
$$

Equation (5) implies equilibrium intra-community conflict allocation must be identical for all members; i.e., $\frac{x_{i g}}{x_{g}}=\frac{1}{n_{g}}$, and that $x_{g}<n_{g}$ (since $\frac{\mu_{g}\left(n_{g}-1\right)}{n_{g}}<1$ ) for any $y_{g} \geq 0$. Furthermore, from (4),

$$
\frac{\partial p_{g}}{\partial y_{i g}}=\frac{z y_{-g}}{\left(y_{A}+z y_{B}\right)^{2}} \text {. }
$$

Together, (6) and (9) yield:

$$
\frac{z y_{-g}}{\left(y_{A}+z y_{B}\right)^{2}}=\frac{\left[\mu_{g}\left(\frac{1}{n_{g}}\right)+\left(1-\mu_{g}\right)\right] L_{g}}{T_{g}} .
$$

Re-introducing the territory sub-script $j$ to pre-empt confusion, define

$$
a_{g j} \equiv \frac{\left[\mu_{g j}\left(\frac{1}{n_{g j}}\right)+\left(1-\mu_{g j}\right)\right] L_{g j}}{T_{g j}} .
$$

Since $n_{g j} \geq 2, a_{g j}$ is declining in the weakness of property rights protection $\mu_{g j}$. It is declining in group population $n_{g j}$ as well. This variable is the opportunity cost of external conflict effort expressed in units of the public good: the numerator is the income loss from shifting a unit of labour from production to external conflict, while the denominator is the monetary value of the public good. From (10)-(11), continuing to suppress the territory subscript $j$ for notational ease, we have:

$$
\frac{y_{B j}}{y_{A j}}=\frac{a_{A j}}{a_{B j}} \equiv a_{A B, j} .
$$

By (12), external conflict effort is inversely proportional to its opportunity cost, so that relative external conflict effort is simply the inverse of the relative opportunity cost of external conflict effort. Hence, using (10)-(12), resource wastage due to inter-community conflict in a territory is given by:

$$
y_{A j}=\frac{z_{j}}{a_{B j}\left(1+z_{j} a_{A B, j}\right)^{2}}, y_{B j}=\frac{z_{j} a_{A B, j}}{a_{B j}\left(1+z_{j} a_{A B, j}\right)^{2}}=\frac{z_{j}^{-1}}{a_{A j}\left(1+z_{j}^{-1} a_{B A, j}\right)^{2}} \text {. }
$$

Thus, $y_{g j}>0$. By (13), the maximum value of $y_{g j}$ is given by:

$$
\bar{y}_{A j}=\frac{1}{4 a_{A j}}, \bar{y}_{B j}=\frac{1}{4 a_{B j}} \text {. }
$$

Using (8), total conflict allocation (resource wastage) in a territory by a group is:

$$
S_{g j} \equiv x_{g j}+y_{g j}=\mu_{g j}\left(n_{g j}-1\right)+\left[\frac{n_{g j}-\mu_{g j}\left(n_{g j}-1\right)}{n_{g j}}\right] y_{g j} \text {. }
$$

Assumption 1. For all $j \in\{1,2\}$, and for all $g \in\{A, B\},\left[\frac{1}{4 a_{g j}}<n_{g j}\right]$.

Given any $n_{g j}$, Assumption 1 must necessarily hold if $\frac{L_{g j}}{T_{g j}}$ is sufficiently high (recall (11)), i.e., if the external conflict benefit-normalized labour productivity is sufficiently high. Assumption 1 is 
sufficient to ensure that the assumption of an interior solution to the individual's maximization problem neither violates the non-negativity constraints on effort allocation, nor the individual's budget constraint. More formally, recalling (8), (13), (14) and (15), Assumption 1 implies the following.

Lemma 1. Let Assumption 1 hold, and let $\left\langle x_{A j}^{*}, x_{B j}^{*}, y_{A j}^{*}, y_{B j}^{*}\right\rangle$ constitute the solution to the equation system (8) and (10). Then, for all $\langle g, j\rangle \in C,\left[x_{g j}^{*}, y_{g j}^{*} \geq 0\right]$ and $\left[n_{g j}>x_{g}^{*}+y_{g j}^{*}\right]$.

Using (8) and (13), we get the resource wastage due to intra-group conflict within a territory:

$$
\begin{aligned}
& x_{A j}=\left[\frac{\mu_{A j}\left(n_{A j}-1\right)}{n_{A j}}\right]\left[n_{A j}-\frac{z_{j}}{a_{B j}\left(1+z_{j} a_{A B, j}\right)^{2}}\right], \\
& x_{B j}=\left[\frac{\mu_{B j}\left(n_{B j}-1\right)}{n_{B j}}\right]\left[n_{B j}-\frac{z_{j} a_{A B, j}}{a_{B j}\left(1+z_{j} a_{A B, j}\right)^{2}}\right] .
\end{aligned}
$$

Furthermore, using (4) and (12), we have the equilibrium shares in a territory:

$$
p_{A j}=\frac{1}{1+z_{j} a_{A B, j}}, p_{B j}=\frac{z_{j} a_{A B, j}}{1+z_{j} a_{A B, j}}=\frac{1}{1+z_{j}^{-1} a_{B A, j}} .
$$

In light of Lemma 1, we then immediately have the following.

Proposition 1. Let Assumption 1 hold. Then, for all $\langle g, j\rangle \in C \equiv\{A, B\} \times\{1,2\}$ :

(i) equilibrium external conflict allocations are given by (13), internal conflict allocations by (16), and shares by (17);

(ii) $y_{g j}$ and $s_{g j}$ both increase as $z_{j}$ increases over $\left(0, a_{B A, j}\right)$, and decline as $z_{j}$ increases over $\left(a_{B A, j}, \infty\right)$, with $\lim _{z_{j} \rightarrow \infty} y_{g j}=0$;

and

(iii) $x_{g j}$ declines as $z_{j}$ increases over $\left(0, a_{B A, j}\right)$, and increases as $z_{j}$ increases over $\left(a_{B A, j}, \infty\right)$, with $\lim _{z_{j} \rightarrow \infty} x_{g j}=\mu_{A j}\left(n_{A j}-1\right)>0$.

By Proposition 1, the external conflict effort of either community in a territory (and hence aggregate external conflict in that territory) increases with the relative (external) conflict efficiency of B in that territory, $z_{j}$, till the latter reaches the relative opportunity cost of external conflict for $\mathrm{B}$, and declines subsequently. Internal conflict behaves in the opposite fashion: the mirror image of external conflict. Nonetheless, total conflict effort by a community within a territory (and thus, overall conflict) follows the pattern of external conflict therein. Hence, output follows the pattern of internal conflict.

In light of Proposition 1, using (2)-(4), (13), (16) and (17), group pay-offs are given by:

$$
\pi_{A j}=\frac{n_{A j} T_{A j}}{1+z_{j} a_{A B, j}}-L_{A j}\left[\frac{n_{A j}-\mu_{A j}\left(n_{A j}-1\right)}{n_{A j}}\right] \frac{z_{j}}{a_{B j}\left(1+z_{j} a_{A B, j}\right)^{2}}+L_{A j}\left(n_{A j}-\mu_{A j}\left(n_{A j}-1\right)\right),
$$




$$
\begin{gathered}
\pi_{B j}=n_{B j} T_{B j}\left(\frac{z_{j} a_{A B, j}}{1+z_{j} a_{A B, j}}\right)-L_{B j}\left[\frac{n_{B j}-\mu_{B j}\left(n_{B j}-1\right)}{n_{B j}}\right] \frac{z_{j} a_{A B, j}}{a_{B j}\left(1+z_{j} a_{A B, j}\right)^{2}} \\
+L_{B j}\left(n_{B j}-\mu_{B j}\left(n_{B j}-1\right)\right) .
\end{gathered}
$$

Noting (18) and (19), Proposition 1 yields the following corollary.

Corollary 1. Let Assumption 1 hold. Then, for all $j \in\{1,2\}, p_{A j}$ declines monotonically as $z_{j}$ increases, with $\lim _{z_{j} \rightarrow 0} p_{A j}=\infty, \lim _{z_{j} \rightarrow \infty} p_{A j}=0$; furthermore, the pay-off of community $A$ in $j$ declines, and that of community $B$ in $j$ rises, monotonically in $z_{j}$.

Proof. See the Appendix.

By Corollary 1, the share of the public good received by A in a territory always declines with an increase in the relative conflict efficiency of B in that territory. Recall that, by Proposition 1(ii), A's output increases as the latter increases beyond $a_{B A, j}$. In this range, the first (share) effect reduces A's pay-off, while the second (output) effect increases it. Corollary 1 implies that the share effect necessarily dominates. Conversely, for $\mathrm{B}$, the two effects move in opposite directions when the relative conflict efficiency of B increases over $\left(0, a_{B A, j}\right)$, with the share effect dominating.

Remark 1. While group contribution to inter-group conflict and individual allocation to intra-group conflict are both determinate in our model, individual contributions to inter-group conflict are indeterminate. The model permits some members of a group to contribute less than others to inter-group conflict, and therefore have greater income, since all group members allocate identical effort to intra-group conflict. Hence, it generates income (and welfare) inequality within a group as an equilibrium outcome, though all group members are endowed with identical amounts of equally productive effort, with the poorer members of the group exhibiting greater engagement in conflict against the other group. Of course, a symmetric equilibrium exists as well, with its associated absence of within-group inequality. Notice that the model rules out a positive association between individual income and extent of participation in conflict against the other group as an equilibrium outcome.

Remark 2. From (8), (11), (13) and (15), internal conflict within a group increases as its labour productivity $L_{g j}$ rises, though external conflict effort, and aggregate conflict effort, both fall, so that group output rises. The positive aggregate output effect, by increasing returns from intragroup expropriatory activities, more than counteracts the production-incentivizing effect of an increase in labour productivity, so that effort wastage on intra-group expropriation expands overall. The same holds for a community-neutral, i.e. equi-proportionate, increase in labour productivity. A community-neutral increase in labour productivity increases the welfare of both communities. 


\section{Cross-territorial spill-over}

We now proceed to embed the idea of cross-territorial spill-over in our model. The basic intuitive idea we formalize is that, as part of the overall public policy package (the composite public good) determined by group contestation over control of government decision-making, bias in the foreign policy of a country reflects the relative strength of the contending groups within. Such bias in foreign policy finds concrete articulation in practical measures to support foreign groups affiliated to the one dominant domestically in their inter-group conflict. External support in turn complements a group's own domestic inter-group conflict effort mobilization, thereby enhancing the efficiency of such effort.

Recall that, for $j \in\{1,2\}, p_{A j}, p_{B j}$ are the shares in territory $j$. Define the relative share, or relative success, $\frac{p_{B j}}{p_{A j}} \equiv p_{B A, j}$. From (17), we have the equilibrium condition:

$$
p_{B A, j}=z_{j} a_{A B, j}
$$

Assumption 2. For all $j \in\{1,2\}, z_{j}=p_{B A,-j}{ }^{\theta}$, where $\theta_{j} \in(0,1)$.

The parameter $\theta_{j}$ in Assumption 2 measures the extent to which dominance in domestic group conflict spills over into, i.e, gets reflected in, the effective bias of foreign policy: it is the elasticity of effective bias in foreign policy with respect to domestic group balance. When $\theta_{1}=\theta_{2}=0$, the model reduces to the standard case of no spill-overs across territories and identical conflict efficiency $\left(z_{1}=z_{2}=1\right)$. Intuitively, this may model the case where differences in identity markers across territories completely trump cross-territorial commonalities within each group, so that the groups (and hence, the state apparatus) maintain perfect neutrality with regard to conflicts elsewhere. Alternatively, this can model the case where actions taken by the residents of one territory have a negligible impact on events in the other territory, because of material constraints such as geographic distance, nature of terrain or lack of resources. When $\theta_{i}>0$, positive spill-overs exist: success in one territory acts as a force enhancer in another. To see this, suppose that $p_{B A, 2} \equiv \frac{p_{B 2}}{p_{A 2}}>1$, so that B is the dominant (i.e., more successful) group in 2. Then, for all $\theta_{2}>0, p_{B A, 2}{ }^{\theta_{2}}>1$; furthermore, $p_{B A, 2}{ }^{\theta_{2}}$ is monotonically increasing in $\theta_{2}$. Thus, greater success in territory 2 on part of the dominant group, B, magnifies the relative effectiveness or productivity of its affiliate's external conflict effort in territory 1 , thereby translating into a higher share in the latter territory for any given deployment of external conflict effort inputs therein by the two parties. The higher the value of $\theta_{2}$, the greater the effective reflection of domestic group balance of power in the foreign policy of territory 2 , and thus 
the greater the extent of spill-overs from 2 to 1 ; hence the higher the relative productivity of external conflict effort deployed in 1 by the affiliate of the group which dominates in $2 .{ }^{10}$

Domestic group bias may intuitively be expected to be reflected in foreign policy, in the sense of partisan financial, military, logistical, organisational and propaganda support (both official and private), to the foreign affiliate of the group that dominates domestically. When external support adds to the domestic mobilization of money, arms, organizers, agitators and fighters for inter-group conflict, our formulation implies that external help augments any given amount of own mobilization of such resources on part of the favoured affiliate group by a proportion $\left(p_{B A,-j}{ }^{\theta_{-j}}-1\right)$. In this sense, external support complements own resource mobilization rather than supplanting it. This specification is consistent with the idea that external sponsors are more likely to increase their support when domestic groups show greater evidence of their own effectiveness, proxied in our model by greater own resource mobilization for inter-group conflict. It abstracts from the possibility that resources provided by external sponsors may subsequently be diverted to intra-group conflict or consumption. In other cases, greater external support may find reflection in greater cross-border access to safe houses, sanctuaries, strategically important roads, mountains, cross-border bases and training camps, diplomatic, media and propaganda support, international lobbying, information sharing, existing stocks of heavy weaponry (esp. tanks, artillery and aircraft) that cannot be easily purchased etc. These diverse forms of external help, which cannot be procured through domestic mobilization, may evidently be viewed as complementary to domestic mobilization of inter-group conflict effort: they augment the efficiency of such effort. ${ }^{11}$ The first class of interventions discussed above typically involves the explicit commitment of significant real resources by the intervening territory; resources that need to be diverted from domestic uses. The second involves more the enabling of foreign affiliates to use domestic territory and public goods such as existing social or security infrastructure and networks: it does not typically require large-scale diversion of resources from domestic use. To keep the model tractable, we shall ignore cross-border real resource commitment in our analysis below. Instead, in all our calculations of resource loss due to conflict, we shall concentrate exclusively on resources committed to domestic conflict in either territory.

${ }^{10}$ In real life, one would expect a finite upper limit on one country's ability to enhance the conflict efficiency of an affiliate group elsewhere. One may incorporate this by amending Assumption 2 to the following: for some $z_{j}, \overline{z_{j}}>0, z_{j}<\overline{z_{j}},\left[z_{j}=z_{j}\right.$ if $p_{B A,-j}{ }^{\theta_{-j}} \leq z_{j} ; z_{j}=p_{B A,-j}{ }^{\theta_{-j}}$ if $p_{B A,-j} \theta_{-j} \in\left(z_{j}, \overline{z_{j}}\right)$, and $z_{j}=\overline{z_{j}}$ if $p_{B A,-j}{ }^{\theta_{-j}} \geq \overline{z_{j}}$ ]. Only the intermediate case $p_{B A,-j} \overline{\theta_{-j}} \in\left(z_{j}, \overline{z_{j}}\right)$ is of interest. Our substantive conclusions, presented in Propositions 2-4 below, will then apply under parametric configurations which satisfy: $\left[a_{A B, 2} \frac{\theta_{2}}{1-\theta_{1} \theta_{2}} a_{A B, 1} \frac{\theta_{1} \theta_{2}}{1-\theta_{1} \theta_{2}} \in\left(\underline{z_{1}}, \overline{z_{1}}\right)\right.$ and $\left.a_{A B, 1} \frac{\theta_{1}}{1-\theta_{1} \theta_{2}} a_{A B, 2} \frac{\theta_{1} \theta_{2}}{1-\theta_{1} \theta_{2}} \in\left(\underline{z_{2}}, \overline{z_{2}}\right)\right]$. The feature that the two groups are equally efficient in inter-group conflict sans spill-overs is for notational simplicity: it can be relaxed to capture cases where one group is inherently more efficient, say because of its traditional control over the military.

11 Arbatskaya and Mialon (2010) provide a formalization of this basic idea of multiple conflict inputs mapped (according to a Cobb-Douglas production function in their case) into an aggregate conflict effort variable. 
We permit spill-overs to be asymmetric: $\theta_{1}$ need not be equal to $\theta_{2}$. Territory 1 may be in a better position to influence group conflict in territory 2 than vice versa. This may reflect the greater responsiveness of foreign policy in 1 to a given domestic balance of ethnic power due to differences in domestic institutions. For example, this may obtain because foreign policy in 2 is determined to a greater extent by a self-replicating elite corps of professional soldiers and diplomats, with commensurately less intervention by politicians, or because 1 is an independent country while 2 is a small constituent province of a federal state, whose other constituents contain neither A nor B. Alternatively, 1 may exhibit greater spill-over than 2 simply because of the strategic nature of its terrain. Greater physical distance or less extensive/porous common borders may be expected in general to proportionately reduce both $\theta_{1}$ and $\theta_{2}$, while the richer territory may be expected to influence events in the poorer territory more effectively than the other way round, simply by virtue of its ability to deploy greater resources. By the same logic, across-the-board increase in wealth within both territories appears intuitively likely to increase spill-overs in both directions. Increase in the wealth of a territory, $j$, may be modelled by an equi-proportionate increase in the labour productivity parameters $L_{A j}, L_{B j}$. It is evident from (11) that such an increase leaves the relative conflict cost $a_{A B, j}$ unchanged. Hence, noting (21) below, it follows that, given the spill-over elasticities $\theta_{1}, \theta_{2}$, such a change in territory $j$ has no effect on conflict in the other territory $(-j)$. Thus, the spill-over effect of an equi-proportionate increase in labour productivity across communities within a territory, $j$, may be uniquely and parsimoniously modelled in terms of an increase in the spill-over elasticity $\theta_{j}$.

Using (20) and Assumption 2, we have:

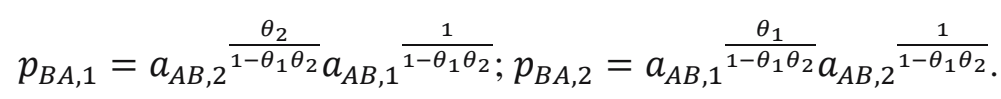

Together, (20)-(21) yield:

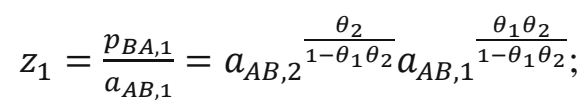

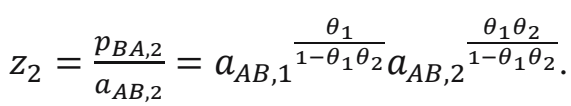

We shall assume that, on (geometric) average, B has an advantage in the opportunity cost of external conflict effort, and adopt the labelling convention that B's advantage in such opportunity cost is at least as high in territory 1 as in territory 2.

Assumption 3. (i) $\bar{a}_{A B} \equiv \sqrt{a_{A B, 1} a_{A B, 2}}>1$, (ii) $a_{A B, 1} \geq a_{A B, 2}$.

Let $a_{A B, 1}=v \bar{a}_{A B}$. By Assumption 3(ii), $v \geq 1$, with the inequality holding strictly if $a_{A B, 2} \leq 1$. We can now address the connection between spill-overs and intra-territory conflict. We first consider a unilateral increase in the ability of the inter-group balance of power in a territory to influence conflict in the other territory (say, due to faster economic growth in the former, or because of a unilateral 
relaxation of import restrictions, restrictions on private aid and capital flows and immigration controls in the latter). We show that such increase may permit a territory to 'export out' its own conflict, i.e., reduce conflict within, while increasing it in the other territory. Thus, greater unilateral economic integration by a country with another may increase conflict and reduce output in the integrating country. This hurts both the dominant group in the integrating territory, and its affiliate in the other.

Proposition 2. Let Assumptions 1-3 hold, and let $\breve{\theta} \equiv \frac{\ln \left(\frac{v}{\bar{a}_{A B}}\right)}{\ln \left(\bar{a}_{A B} v\right)}$.

(i) If $a_{A B, 2} \geq 1$, then external and total conflict fall, and internal conflict rises, in both territories as either $\theta_{1}$ or $\theta_{2}$ increases. B's share and pay-off both rise, and those of A fall, in both territories.

(ii) If $a_{A B, 2}<1$, then, for all $j \in\{1,2\}$, external and total conflict fall, and internal conflict rises, in territory $j$ as $\theta_{j}$ rises. B's share and pay-off both rise, and those of A fall, in territory 1 if $\theta_{1}$ rises. B's share and pay-off both fall (resp. rise), and those of A rise (resp. fall), in territory 2 if $\theta_{2}$ rises, when $\theta_{1}<$ (resp. $\left.>\right) \breve{\theta}$, with $\breve{\theta} \in(0,1)$.

(iii) If $a_{A B, 2}<1$, then, for all $j \in\{1,2\}$, external and total conflict rise (resp. fall), and internal conflict falls (resp. rises), in territory $j$ as $\theta_{-j}$ rises when $\theta_{1}<($ resp. $>$ ) $\breve{\theta}$. B's share and pay-off both rise, and those of A fall, in territory 2 if $\theta_{1}$ rises. B's share and pay-off both fall (resp. rise), and those of A rise (resp. fall), in territory 1 if $\theta_{2}$ rises when $\theta_{1}<($ resp. $>$ ) $\breve{\theta}$, with $\breve{\theta} \in(0,1)$.

Proof: See the Appendix.

By Proposition 2(i), if one community, say B, has an external conflict cost advantage in at least one territory, and no disadvantage in either territory, then external conflict falls monotonically in both territories if either acquires greater ability to influence conflict in the other (i.e., as the effective foreign policy elasticity, or extent of spill-over, $\theta_{j}$, increases for either). Total conflict falls as well in both territories, while internal conflict and output both rise. The dominant group B unambiguously benefits in both territories. Thus, in this case, stronger cross-territorial spill-over reduces conflict (thereby increasing output) overall, but increases inter-community inequality in both territories.

From (21), given Assumption 3, and given $a_{A B, 2}<1, p_{B A, 2}>1$ iff $\theta_{1}>\frac{\ln a_{B A, 2}}{\ln a_{A B, 1}}$. Parts (ii)(iii) of Proposition 2 consider the case where B has a cost disadvantage in territory 2, which is at least compensated by a cost advantage in 1 (recall Assumption 3). Suppose that territory 1's ability to influence conflict in 2 is relatively low, so that B is the dominated (less successful) party in the inter- 
communal conflict in 2, though it is the dominant party in 1 . This obtains when $\theta_{1}$ is below the threshold $\left.\frac{\ln \left(\frac{v}{\bar{a}_{A B}}\right)}{\ln \left(\bar{a}_{A B} v\right)}\right)$. Then an increase in the ability of the group balance of power in either territory to influence conflict in the other territory reduces both external and total conflict in the former but increases them in the latter. Thus, greater spill-over from a territory enhances inter-group peace (and thereby output) within, but aggravates inter-group conflict (and reduces output) outside, that territory. Greater spill-over from a territory benefits the dominant community in that territory, in both territories. For example, greater spill-over from 2 benefits $\mathrm{A}$ in both territories. The threshold $\frac{\ln \left(\frac{v}{\bar{a}_{A B}}\right)}{\ln \left(\bar{a}_{A B} v\right)}$ is higher, the lower the mean relative cost $\bar{a}_{A B}$. Thus, the lower the cost advantage for B on average, the larger the interval for $\theta_{1}$ over which these claims hold. In the limit, when neither community has a cost advantage on average, but each has a cost advantage in one territory, exactly neutralized by its cost disadvantage in the other territory, they must hold for all $\theta_{1} \in(0,1)$.

Note that, regardless of the extent of spill-over from 2 to $1\left(\theta_{2}\right)$, the group with a cost advantage overall, B, is always the dominant group in 1 (see part (iii) in the proof of Proposition 2).

By Proposition 2, when each community has a cost advantage in one territory, a simultaneous increase in conflict spill-over from both territories has contradictory effects. What is the net effect of such an increase? We now address this issue. We consider an equi-proportionate increase in conflict spill-overs, which increases their geometric mean but not their relative proportion, Intuitively, this may be expected to reflect lower geographic distance (or longer common borders) between the two territories, similar economic growth, or an expansion in bilateral trade and labour market integration. We interpret it as capturing greater bilateral economic integration. We find that an equi-proportionate increase in spill-over elasticities affects group conflict in a non-monotone fashion within each territory. This initially increases group conflict in both territories; at intermediate levels it moves conflict in opposite directions across territories; at already high levels of integration it reduces conflict in both territories. It may affect the welfare of a group and its affiliate in opposite ways.

Proposition 3. Let Assumptions 1-3 hold, let $\theta \equiv \sqrt{\theta_{1} \theta_{2}}, \theta_{1}=w \theta, \theta_{2}=w^{-1} \theta$, and suppose $a_{A B, 2}<$ 1. Define $\breve{\theta} \equiv \frac{\ln \left(\frac{v}{\bar{a}_{A B}}\right)}{\ln \left(\bar{a}_{A B} v\right)}$. Then there exists $\varepsilon \in(0,1)$ such that, for all $w>\varepsilon$, the following must hold. (i) An increase in $\theta$ over $\left(0, \frac{\breve{\theta}}{w}\right)$ increases external and total conflict in territory 2, while reducing internal conflict within each community in that territory; whereas an increase in $\theta$ over $\left(\frac{\breve{\theta}}{w}, 1\right)$ reduces external and total conflict in territory 2, while increasing internal conflict within each community in that territory; with $\frac{\breve{\theta}}{w} \in(0,1)$. The share and pay-off of community $B$ both rise in 2 , while the pay-off of community A falls. 
(ii) There exists $\theta^{*} \in\left(0, \frac{\breve{\theta}}{w}\right)$ such that an increase in $\theta$ over $\left(0, \theta^{*}\right)$ increases external and total conflict in territory 1, while reducing internal conflict within each community in that territory; whereas an increase in $\theta$ over $\left(\theta^{*}, 1\right)$ reduces external and total conflict in territory 1 , while increasing internal conflict within each community in that territory. An increase in $\theta$ over $\left(0, \theta^{*}\right)$ increases both the share and the pay-off of community $A$, while reducing the pay-off of community $B$; an increase in $\theta$ over $\left(\theta^{*}, 1\right)$ reduces both the share and the pay-off of community $A$, while increasing the pay-off of community $B$.

(iii) $\frac{\partial\left(\frac{\bar{\theta}}{w}\right)}{\partial w}, \frac{\partial\left(\theta^{*}\right)}{\partial w}, \frac{\partial\left(\frac{\breve{\theta}}{w}\right)}{\partial \bar{a}_{A B}}, \frac{\partial\left(\theta^{*}\right)}{\partial \bar{a}_{A B}}<0$.

Proof. See the Appendix.

By Proposition 3, inter-group conflict initially rises in both territories as our measure of bilateral integration, the mean spill-over elasticity $\theta$, rises from 0 (intuitively, bilateral autarchy), till it reaches some threshold value; it falls in both territories as $\theta$ rises further, beyond some other threshold value. In between, a rise in $\theta$ increases external conflict in one territory, but reduces it in the other. Total conflict behaves in the same fashion, while internal conflict and social output behave in the opposite fashion. Thus, in this intermediate case, greater bilateral integration has contradictory effects on conflict across territories. This is illustrated in Figure 1 below. In Figure 1, the unbroken inverted-U shaped schedule on top shows how inter-group (and aggregate) conflict behaves in territory 1, while the broken schedule below shows the behavior of inter-group (or aggregate) conflict in 2. External and total conflict rise with the level of spill-over in both territories over the interval $\left(0, \theta^{*}\right)$, while they fall in both territories in response to greater bilateral integration over the interval $\left(\frac{\breve{\theta}}{w}, 1\right)$. Over the intermediate interval $\left(\theta^{*}, \frac{\breve{\theta}}{w}\right)$, greater spill-over increases external and total conflict in territory 2 (where B has a cost disadvantage), but reduces them in territory 1 (where B has a cost advantage).

\section{Insert Figure 1.}

Greater bilateral integration unambiguously benefits B in the territory where it has a cost disadvantage (2), but may possibly (though not necessarily) hurt that community in the territory where it has a cost advantage (1). Greater bilateral integration initially benefits the cost disadvantaged group in both territories. Thus, A in 1 and B in 2 both achieve greater success in their respective inter-group conflicts and achieve welfare gains. This is associated with greater external (and total) conflict in both territories. Despite its gains, A always remains the dominated (lower share) group in 1. Beyond a threshold level $\left(\theta^{*}\right)$, the identity of the beneficiary group gets reversed in 1 . Further increases in bilateral integration come to benefit the cost advantaged (and dominant) group, B, in 1, while reducing inter-group (and aggregate) conflict in that territory. Such a reversal does not occur in 2. Increases in bilateral integration continue to benefit the cost disadvantaged group, B, in 2. Eventually, 
spill-over effects from 1 come to outweigh B's cost disadvantage in 2, so that B becomes the dominant (higher share) group in the external conflict in 2. Further increases in bilateral integration increase B's dominance (share) even more, while also reducing inter-group conflict in 2. Thus, so long as B's cost disadvantage in 2 is reflected in B being less successful than A in the inter-group conflict in 2, a marginal increase in bilateral integration increases inter-group and aggregate conflict in that territory. This is depicted in Figure 2. The unbroken U-shaped schedule illustrates the behavior of B's relative share in 1, while the broken U-shaped schedule below depicts the movement of B's relative share in 2.

\section{Insert Figure 2.}

By Proposition 3(iii), both the threshold values rise if either $\bar{a}_{A B}$ or $w$ falls. Hence, since $\bar{a}_{A B}>1$ by Assumption 3(i), the more the communities are similar on average in their conflict cost, the more likely it is that greater bilateral integration will increase conflict in both countries. The lower the relative spill-over elasticity of territory 1 (where the community with overall cost advantage, $\mathrm{B}$, dominates), the more likely that greater bilateral integration will increase conflict in both countries.

The single-peak property of inter-group (and aggregate) conflict, stated in Proposition 3 and depicted in Figure 1, need not hold when $w$ is sufficiently close to 0.

When the same community cost-dominates in both territories, an equi-proportionate increase in spill-overs benefits the dominant community, magnifying its share and pay-off in both territories. Since $p_{A j}$ tends to 0 as $\theta$ tends to 1 , even an infinitesimally small advantage in external conflict cost translates into an arbitrarily large advantage in conflict success if the mean spill-over elasticity $\theta \in$ $(0,1)$ is sufficiently close to 1 . Thus, stronger spill-overs all around imply higher shares of the dominant community in this case. One may interpret this in the spirit of a 'knife-edge' result. Suppose, initially, the two communities faced identical costs of engaging in conflict, so that they shared the prize equally in the two territories. Now suppose, due to some change in the economic environment, the relative conflict cost shifts marginally in favour of B in just one territory. Even such a localized and marginal change can have arbitrarily large global consequences for conflict outcomes: it can increase the relative share of B in both territories to an arbitrarily large extent when crosslocation identification leads to spill-over effects that are sufficiently intense and pervasive.

\section{Cost effect spill-over}

How do changes in the fundamentals of a society such as population size, population composition, degree of private property rights protection and relative productivity within a territory affect conflict and distribution in the other territory? We now turn to this question.

Define, for all $g \in\{A, B\}$ and all $j \in\{1,2\}, l_{g j} \equiv \frac{L_{g j}}{T_{g j}}, l_{A B, j} \equiv \frac{l_{A j}}{l_{B j}}, \alpha_{j} \equiv \frac{n_{A j}}{n_{j}}$. Thus, $l_{A B, j}$ is the relative productivity of community $\mathrm{A}$ in territory $j$, and $\alpha_{j} \in(0,1)$ is the population share of community $A$ in territory $j$. Using (11)-(12), we have the relative conflict cost of A in territory $j$ : 


$$
a_{A B, j} \equiv \frac{\left[\mu_{A j}+\left(1-\mu_{A j}\right) \alpha_{j} n_{j}\right]}{\left[\mu_{B j}+\left(1-\mu_{B j}\right)\left(1-\alpha_{j}\right) n_{j}\right]}\left[l_{A B, j} \frac{\left(1-\alpha_{j}\right)}{\alpha_{j}}\right] .
$$

By (24), the relative conflict cost in a territory depends on its total population, population composition, relative productivity, and property rights protection. These variables affect the balance of power (relative success) in domestic group conflict (recall (20)), which spills over into group conflict in the other territory, by affecting relative conflict efficiency in the latter (Assumption 2 and (21)). What is the nature of such extra-territorial influences on conflict within a territory? We now proceed to answer this question. We focus on the case where A, the community with a conflict cost disadvantage on average (Assumption 3 ) is the minority community in both territories $\left(\alpha_{j} \in\left(0, \frac{1}{2}\right)\right.$ ).

Proposition 4. Let Assumptions 1-3 hold, let $\breve{\theta} \equiv \frac{\ln \left(\frac{v}{\bar{a}_{A B}}\right)}{\ln \left(\bar{a}_{A B} v\right)}$, and, for all $j \in\{1,2\}$, assume $\left[\mu_{j}=\right.$ $\mu_{A, j}=\mu_{B, j}$ and $\left.\alpha_{j} \in\left(0, \frac{1}{2}\right)\right] . \quad$ Define $Q_{j} \equiv\left\{l_{B A, j}, n_{j}, \alpha_{j},\left(1-\mu_{j}\right)\right\}$. Then the following must hold.

(i) If $a_{A B, 2} \geq 1$, then, for all $j \in\{1,2\}$, and for all $q_{j} \in Q_{j}$, a marginal increase in $q_{j}$ increases external and total conflict in territory $-j$, while decreasing internal conflict and output within each community in that territory.

(ii) If $a_{A B, 2}<1$, then: (a) provided $\theta_{1} \in(0, \breve{\theta})$, a marginal increase in any $q_{1} \in Q_{1}$ decreases external and total conflict in territory 2, while increasing internal conflict and output within each community in that territory; and (b) provided $\theta_{1} \in(\breve{\theta}, 1)$, a marginal increase in any $q_{1} \in Q_{1}$ increases external and total conflict in territory 2, while decreasing internal conflict and output within each community in that territory.

(iii) If $a_{A B, 2}<1$, then a marginal increase in any $q_{2} \in Q_{2}$ increases external and total conflict in territory 1, while decreasing internal conflict and output within each community in that territory.

(iv) For all $j \in\{1,2\}, p_{A j}$ rises as any $q_{-j} \in Q_{-j}$ increases; furthermore, the pay-off of community $A$ in $j$ rises, and that of community $B$ in $j$ declines, monotonically in all $q_{-j} \in Q_{-j}$.

Given Assumptions 1-3, suppose A is the minority in both territories, and suppose property rights protection is the same across communities within a territory (though it may vary across territories). Then, by Proposition 4(i), provided A does not have a cost advantage in either territory, a sharepreserving population increase in any territory increases both external and total conflict in the other territory. The same effect obtains if, in any territory, either the minority's population share increases (without reducing total population), or property rights protection weakens uniformly across the territory, or the majority community achieves an increase in its relative labour productivity. By Proposition 4(iii), if the minority has a conflict cost advantage in 2, then such changes in that territory (2) must always increase both aggregate and total conflict in 1. By Proposition 4(ii), given that the minority has a conflict cost advantage in 2, but a disadvantage on average, such changes in 1 will 
increase both aggregate and total conflict in 2 when 1's ability to influence conflict in 2 (i.e., $\theta_{1}$ ) is sufficiently high, so that the minority is the dominated (less successful) community in 2 (as well as in 1). The higher the value of average relative cost of conflict for the minority $\left(\bar{a}_{A B}\right)$, i.e. the farther apart the two communities are on average in terms of their conflict cost, the lower the threshold value $\breve{\theta}$ : hence the larger the range of spill-over values from 1 to 2 over which this holds. Thus, when the majority community has a large cost advantage on average, changes in the parameters under focus have the same effect on conflict in the other territory, irrespective of the location of such changes.

In sum, therefore, population increase in a territory that does not reduce the minority's share, an enlargement of the minority that does not reduce total population, weaker property rights protection across communities, and an increase in the relative labour productivity of the majority community, all causally increase both inter-group and aggregate conflict in the other territory, when the minority community is the dominated one in both territories. However, when the minority community dominates in one territory, but is dominated in another, such changes in one territory may increase or decrease inter-group and aggregate conflict in the other territory, depending on which territory the changes occur in. These changes nonetheless always make the minority in the other territory better off, while making the majority therein worse off (Proposition 4(iv)).

The assumption that property rights protection is at least as strong within the minority as within the majority community $\left(\mu_{B j} \geq \mu_{A j}\right.$ ) actually suffices for the claim regarding the effects of a cross-community improvement in property rights protection within a territory. If $\mu_{B j}>\mu_{A j}$, the claim continues to hold if A is the minority in both territories, and may hold even if A constitutes the majority in one, or both, territories. If $\mu_{B j}>\mu_{A j}$, the claim regarding the effect of a share-preserving population increase continues to hold if A constitutes a sufficiently small minority in both territories. Given identical property rights protection across communities, the claim regarding the effect of an increase in the minority's population share (with constant total population) may hold even if A constitutes the majority in one, or both, territories. The claim regarding the effect of an increase in relative productivity holds independently of any assumption, regarding property rights protection across communities or the population share of the cost disadvantaged community, A, whatsoever. ${ }^{12}$

Given our assumptions, within a territory, $j$, a growth rate of the minority population at least as high as that of the majority (with non-decreasing total population), weaker property rights protection across communities, and higher relative labour productivity of the majority community, all increase the relative conflict cost of the majority, B (Lemma 4 in Appendix 1). The minority, A, is consequently more successful in its conflict with the majority in the territory, $j$, where these changes occur. The impacts on conflict and group pay-offs within $j$ are, however, ambiguous in general, since such changes affect conflict and pay-offs within $j$ through multiple channels.

\footnotetext{
12 See Lemma 4 in Appendix 1 for formal statements and proofs of these generalizations.
} 


\section{Discussion and concluding remarks}

In this paper, we have developed a parsimonious model of simultaneous between-group ('ethnic') conflict over public goods with group-specific non-monetary benefits (state 'culture' or 'religion'), decentralized intra-group distributive conflict over private consumption ('income'), and production, with conflict spill-overs across politico-administrative territories such as countries or provinces of a country. Our theoretical analysis generates a number of empirically testable propositions regarding the nature of extra-territorial influences on intra-territorial (or domestic) conflict.

A large empirical literature has developed on the connection between greater market openness, globalization and domestic conflict. ${ }^{13}$ The theoretical results in this paper complement, and offer new organizing principles for, such empirical research. It is typically difficult, if not impossible, to prevent partisan political aid, both financial and material, from being routed through standard aid, investment and business transaction channels, just as it is difficult to prevent activists from utilizing entry procedures intended for economic migrants and refugees. Greater economic integration also makes the integrating country more susceptible to external pressures in the form of trade and investment sanctions. Our Proposition 2 thus implies that greater unilateral economic integration by a country with another country or region, through unilateral relaxation of import restrictions, restrictions on private aid and capital flows and immigration controls, may increase ethnic conflict and reduce output in the integrating country or region, by making it more susceptible to external political influences. This happens when the dominant group in one country is affiliated to the dominated group in another. The current debates over the absorption of Arab refugees in Europe and North America, and their political fall-outs, may, for example, be understood in this light. The vulnerability of Nepal to Indian economic pressure over the constitutional status of the minority Madhesi community (ethno-linguistic groups of Indian origin inhabiting the southern part of Nepal), and the ongoing conflict between Madhesi political groups and the Nepali state, may also be seen in this light. ${ }^{14}$ The country whose influence on the integrating country expands may thus be able to 'export out' its own ethnic conflict, i.e., reduce such conflict within. Faster growth in a country, by increasing its ability to influence conflict within its neighbours, may likewise reduce domestic ethnic conflict, while increasing it within its neighbours. The links between sustained economic growth in

\footnotetext{
${ }^{13}$ See, for example, Magee and Massoud (2011) and Barbieri and Reuveny (2005) for discussions.

14 In late 2015, Nepal sought UN intervention against India over prolonged obstruction of a key border trade point by Madhesi agitators that resulted in acute shortage of essential goods in Nepal. Its Prime Minister blamed India for prolonging the blockade. (http://www.theguardian.com/globaldevelopment/2015/nov/18/nepal-border-blockade-india-threatens-future-un-unicef) It has been widely suggested in the Indian media that the federal governing party, the BJP, sought to use the Madhesi agitation to strengthen its own position in the key Indian state of Bihar, where it is in the opposition. The Madhesis share strong ethno-linguistic and caste ties with important sections of the population of northern Bihar.
} 
Saudi Arabia and Turkey in the last 15 years or so, relative domestic stability therein, and current Shia-Sunni conflicts in Iraq, Syria, Lebanon and Yemen, all countries where Sunnis have constituted a dominated group, may be viewed in this light, especially when juxtaposed against the relative stagnation of the Iranian economy during this period. ${ }^{15}$ The finding by Collier and Hoeffler (2004), that countries with large diasporas in the US are more likely to experience civil war, may also be rationalized by our result, when the diaspora constitutes largely of an ethnic group dominated in its source country (e.g. Tamils from Sri Lanka or Catholics from Northern Ireland). When the dominant group in one country is affiliated to the dominant group in another, greater unilateral integration by either country reduces ethnic conflict in both. Conversely, in this case, a diminution in such integration, or, more generally, in the ability of either country to influence events in the other country, due to domestic economic stress or political developments caused by defeats in wars elsewhere, increases ethnic conflict in both countries. The conflict between Algerians and French settlers in Algeria, and between Algerian immigrants and sections of the French population in France, during the years of the Algerian War (1954-62), may be understood thus, coming as it did in the aftermath of a weakening of French military and economic power due to its defeat first in WW II and subsequently in Indo-China. The conflict was resolved in Algeria only by the wholesale relocation of the settlers to France immediately after independence, and continues till date in France in various forms.

Proposition 3 shows that, when the external affiliate of the dominant group in one country would be dominated without external support, greater bilateral integration initially increases ethnic conflict in both countries. Thus, starting from autarchy, greater integration of markets across borders may initially increase ethnic conflict on both sides. ${ }^{16}$ This helps to understand the rise of xenophobic politics in the affected countries, such as, for example, the simultaneous rise of Islamists in the Maghreb and the anti-immigrant, anti-Muslim National Front in France, over the last quarter century. Greater bilateral integration may reduce ethnic conflict in both countries/regions at very high levels of such integration, when one becomes a political 'dependency' of another, in that the dominant group in the former owes that status solely to support from the latter. In the context of conflict reduction, there may thus be an 'all or nothing' aspect to bilateral integration. The long periods of relative ethnic peace found in the history of the multi-ethnic Ottoman and Austro-Hungarian empires are consistent with this argument, associated as they were with the dominance, respectively, of minority Turkish and

15 This holds for Iraq since the fall of Saddam Hussein, whereas Syria has been under Shia (Alawaite) domination (albeit as a secular regime) since 1970, when Hafez al-Assad took power. In Lebanon, Sunnis constitute roughly the same proportion of the population as Shias. During the Syrian occupation (1976-2005), and subsequently, Sunni political groups have generally opposed Syria and Iran, while Shia groups such as Hezbollah and Amal have been in support. Ali Abdullah Saleh, President of North Yemen from 1978 until its reunification with South Yemen in 1990, and President of Yemen from 1990 to 2012, is a Shia who has openly sided with the Shia Houthi insurgent group. His Saudi-backed successor, Abd Rabbuh Mansur Hadi, is a Sunni.

16 Dal Bo' and Dal Bo' (2011) find that free trade may lead to greater income expropriation and thus lower welfare within a country, but do not address group conflict over public goods or conflict spill-overs at all. 
German elites throughout regions populated by other ethnic groups. This dominance was due to support from the respective imperial centres, and was gradually eliminated, to the accompaniment of group violence and ethnic cleansing, as ties between imperial centres and the provinces weakened with the rise of local nationalisms over the 19th century, eventually to collapse after WW I. ${ }^{17}$

Proposition 4 reveals causal connections between ethnic conflict within a country and key characteristics of its neighbours, or, more generally, countries with which it has strong trade and immigration linkages. Ceteris paribus, being situated next to a more populous neighbour may make a country more conflict-prone. A growing empirical literature, based on cross-country analysis, finds a positive association between ethnic polarization and ethnic conflict within countries. ${ }^{18}$ In a twocommunity framework, an increase in the relative size of the minority implies greater ethnic polarization. Our findings thus offer theoretical grounds for the claim that greater ethnic polarization within its neighbours may causally imply greater ethnic conflict inside a country. Ethnic occupational specialization and locational segregation imply that trade and labour market deregulation, and privatization of public sector units, may affect different ethnic groups differently, as may environmental degradation. If such deregulation and privatization (or environmental degradation) in a neighbouring country or territory affect the economic opportunities of majority and minority ethnic groups therein differently, they may influence group conflict within a country, in ways identified in Proposition 4. A general, country-wide weakening or collapse of the state machinery (and thus of property rights protection), due to civil war and external intervention (as in contemporary Iraq, Libya, Syria and Afghanistan) or due to a sustained economic crisis (as afflicted most successor states of the Soviet Union in the 1990s), may turn neighbouring countries more fragile and conflict-ridden.

Lastly, the direct effect of a community-neutral increase in labour productivity within a territory reduces both inter-group and aggregate conflict, but increases intra-group conflict and group output within both communities (recall Remark 2) in that territory. These domestic effects are all strengthened if the consequent economic growth indirectly expands that territory's ability to influence ethnic conflict in the other territory (recall Proposition 2).

\footnotetext{
17 Beginning in the mid-19th century, hundreds of thousands of Muslims (Turks, Circassians and Chechens) were expelled from the Caucasus and the Balkans, settling in Anatolia, as a result of the Russo-Turkish and Balkan wars. This culminated in the expulsion of almost the entire Turkish population of Greece in 1923. Ottoman forces in turn massacred and expelled the Christian (Armenian, Assyrian and Greek) minorities in Anatolia during WW I and its aftermath. Similarly, large German minorities in every successor state of the Austro-Hungarian empire other than Austria, and in Poland, contributed both to ethnic conflict within these states, and the rise of Nazism in Germany and Austria, in the inter-war period. German minorities in Sudetenland and the Danzig Corridor provided immediate excuses for Hitler's invasions, respectively, of Czechoslovakia and Poland. After WW II, extensive deportations of Germans took place in these countries. Ferguson (2006) discusses the connection between collapse of empires and ethnic violence in the $20^{\text {th }}$ century.

${ }^{18}$ Montalvo and Reynal-Querol $(2005,2008)$ find that societies which are ethnically more polarized, i.e. where majority and minority communities are closer in size, may be more prone to social conflicts (specifically civil wars and genocides). Easterly et al. (2006) present a similar finding in the context of mass killings.
} 
Our conclusions need to be confronted with data, especially in a cross-country context. In recent years, contest-theoretic models have been subjected to experimental investigation (see Dechenaux et al., 2014, for a survey). Our model may also be usefully subjected to experimental scrutiny. At a theoretical level, four extensions are of particular interest. First, one may examine the consequences of conflict spill-overs using contest success functions other than the Tullock formulation used in this paper. Second, one may use alternatives to our summative specification for each community's aggregate group conflict effort, such as the best shot or weakest link formulations, or, indeed, a general constant elasticity of substitution aggregation (e.g. Kolmar and Rommeswinkel, 2013). Third, the effect of asymmetries within a group, in terms of subgroups of different sizes and different intra-subgroup sharing rules, may be explored. Fourth, there may plausibly be contexts where greater success (share) in inter-group conflict for a community, A, in territory 1 reduces its share in territory 2. Intuitively, this may happen because greater success for A in 1 polarizes territory 2 more sharply along identity divides: sections of the other community, B, in 2, develop greater antagonism towards $\mathrm{A}$ in 2, and perceive $\mathrm{A}$ as more of a threat, in response. Thus, identity leads to conflict, which in turn strengthens identity. Alternatively, this may happen because large numbers of $B$ individuals in 1 shift effort to the group conflict in 2, physically migrating there, and/or large numbers of $\mathrm{A}$ individuals in 2 migrate to 1 . The first mechanism involves the idea of an 'identity backlash' and a consequent feedback loop. ${ }^{19}$ The second involves increasing returns to scale in group conflict, momentum and bandwagon effects, as well as the desire to benefit from a larger existing share of the group-specific public good. ${ }^{20}$ It is intuitively easy to see that both these mechanisms, which may operate simultaneously, counteract the tendencies highlighted in our analysis, and, when stronger than the latter, are likely to generate equilibria that involve the effective resolution of ethnic conflict, through the creation of what are, in effect, mono-ethnic territories, with large-scale ethnic cleansing and exchange of population when the second mechanism operates, and cultural/religious assimilation of the weaker group to the stronger one otherwise. This is in contrast to our focus on a situation of persistent ethnic conflict in equilibrium, which presupposes a stable and non-trivial division of the population within a territory into competing ethnic identity groups. Both cases therefore require a theoretical apparatus very different from the one developed in this paper. In real world conflict contexts, persistent ethnic conflict may and often does tip over into ethnic cleansing and population exchange (as happened for example in central and eastern Europe in the first half of

\footnotetext{
${ }^{19}$ Examples are the sharp rise in anti-Hindu violence in Bangladesh in 1992-93, subsequent to the demolition of the Babri Masjid and anti-Muslim riots in India, and Hitler's use of the Sudetenland and Danzig Corridor issues.

20 The decisions of thousands of individuals from many countries to relocate to areas controlled by the ISIL constitute an illustration, when such decisions are permanent. However, such decisions are in line with our model when they are temporary, undertaken with the intention of acquiring military and political training, to be deployed on return in the country of origin. Callander (2007) has shown how bandwagon and momentum might develop in sequential voting, driven by a combination of beliefs and the desire of voters to vote for the winning candidate. Some of these effects may work in a substantively analogous manner in our very different context.
} 
the $20^{\text {th }}$ century, recall footnote 17 ), and thus analysis of these cases would complement the analysis in this paper. We look forward to extensions and developments along the above-discussed lines.

\section{Appendix}

Proof of Corollary 1. The claim regarding $p_{A j}$ follows directly from (17). Using (18), and dropping the subscript $j$ for notational simplicity,

$$
a_{B}\left(1+z a_{A B}\right)^{2} \frac{\partial \pi_{A}}{\partial z}=-n_{A} T_{A} a_{A}-L_{A}\left[\frac{n_{A}-\mu_{A}\left(n_{A}-1\right)}{n_{A}}\right]+2 L_{A}\left[\frac{n_{A}-\mu_{A}\left(n_{A}-1\right)}{n_{A}}\right]\left[\frac{z a_{A B}}{1+z a_{A B}}\right] .
$$

Now, $\lim _{z \rightarrow \infty} \frac{z a_{A B}}{1+z a_{A B}}=1$, and $\frac{z a_{A B}}{1+z a_{A B}}$ is increasing in z. Hence, using (11), for any $z \in(0, \infty)$, the RHS of (N1) is less than $\left(n_{A}-1\right)\left(\mu_{A}\left[1-\frac{1}{n_{A}}\right]-1\right)<0$. Thus, $\frac{\partial \pi_{A}}{\partial z}<0$. Again, using (19),

$$
a_{B}\left(1+z a_{A B}\right)^{2} \frac{\partial \pi_{B}}{\partial z}=n_{B} T_{B} a_{A}-L_{B}\left[\frac{n_{B}-\mu_{B}\left(n_{B}-1\right)}{n_{B}}\right] a_{A B}+2 L_{B} a_{A B}\left[\frac{n_{B}-\mu_{B}\left(n_{B}-1\right)}{n_{B}}\right]\left[\frac{z a_{A B}}{1+z a_{A B}}\right] .
$$

The RHS of (N2) is increasing in $z$. Suppose it is non-positive at $z=0$. Then $n_{B} a_{B} \leq \frac{L_{B}}{T_{B}}[1-$ $\left.\frac{\mu_{B}\left(n_{B}-1\right)}{n_{B}}\right]$, or, using (11), $\left[1 \leq \frac{1}{n_{B}}\right]$, a contradiction, since $n_{B} \geq 2$. Hence $\frac{\partial \pi_{B}}{\partial z}>0$.

Proof of Proposition 2. Equations (22) and (23) reduce respectively to:

$$
\begin{aligned}
& z_{1}=\bar{a}_{A B} \frac{\theta_{2}\left(1+\theta_{1}\right)}{1-\theta_{1} \theta_{2}} v^{\frac{-\left(1-\theta_{1}\right) \theta_{2}}{1-\theta_{1} \theta_{2}}} ; \\
& z_{2}=\bar{a}_{A B} \frac{\theta_{1}\left(1+\theta_{2}\right)}{1-\theta_{1} \theta_{2}} v^{\frac{\left(1-\theta_{2}\right) \theta_{1}}{1-\theta_{1} \theta_{2}}} .
\end{aligned}
$$

In turn, (N3) and (N4) yield, respectively:

$$
\begin{aligned}
& \ln z_{1}=\frac{\theta_{2}\left(1+\theta_{1}\right)}{1-\theta_{1} \theta_{2}} \ln \bar{a}_{A B}-\frac{\left(1-\theta_{1}\right) \theta_{2}}{1-\theta_{1} \theta_{2}} \ln v ; \\
& \ln z_{2}=\frac{\theta_{1}\left(1+\theta_{2}\right)}{1-\theta_{1} \theta_{2}} \ln \bar{a}_{A B}+\frac{\left(1-\theta_{2}\right) \theta_{1}}{1-\theta_{1} \theta_{2}} \ln v .
\end{aligned}
$$

From (N5) and (N6), we have:

$$
\begin{aligned}
& \frac{1}{z_{1}} \frac{\partial z_{1}}{\partial \theta_{1}}=\frac{\theta_{2}}{\left(1-\theta_{1} \theta_{2}\right)^{2}}\left[\left(1+\theta_{2}\right) \ln \bar{a}_{A B}+\left(1-\theta_{2}\right) \ln v\right]=\frac{\theta_{2}}{\left(1-\theta_{1} \theta_{2}\right)^{2}}\left[\ln \left(\bar{a}_{A B} v\right)\left(\frac{\bar{a}_{A B}}{v}\right)^{\theta_{2}}\right] ; \\
& \frac{1}{z_{1}} \frac{\partial z_{1}}{\partial \theta_{2}}=\frac{1}{\left(1-\theta_{1} \theta_{2}\right)^{2}}\left[\left(1+\theta_{1}\right) \ln \bar{a}_{A B}-\left(1-\theta_{1}\right) \ln v\right]=\frac{1}{\left(1-\theta_{1} \theta_{2}\right)^{2}}\left[\ln \left(\frac{\bar{a}_{A B}}{v}\right)\left(\bar{a}_{A B} v\right)^{\theta_{1}}\right] ; \\
& \frac{1}{z_{2}} \frac{\partial z_{2}}{\partial \theta_{1}}=\frac{1}{\left(1-\theta_{1} \theta_{2}\right)^{2}}\left[\left(1+\theta_{2}\right) \ln \bar{a}_{A B}+\left(1-\theta_{2}\right) \ln v\right]=\frac{1}{\left(1-\theta_{1} \theta_{2}\right)^{2}}\left[\ln \left(\bar{a}_{A B} v\right)\left(\frac{\bar{a}_{A B}}{v}\right)^{\theta_{2}}\right] ; \\
& \frac{1}{z_{2}} \frac{\partial z_{2}}{\partial \theta_{2}}=\frac{\theta_{1}}{\left(1-\theta_{1} \theta_{2}\right)^{2}}\left[\left(1+\theta_{1}\right) \ln \bar{a}_{A B}-\left(1-\theta_{1}\right) \ln v\right]=\frac{\theta_{1}}{\left(1-\theta_{1} \theta_{2}\right)^{2}}\left[\ln \left(\frac{\bar{a}_{A B}}{v}\right)\left(\bar{a}_{A B} v\right)^{\theta_{1}}\right] .
\end{aligned}
$$

We first establish the following lemma.

Lemma 2. Given Assumptions 1-3, the following must hold. 
(i) For all $j \in\{1,2\}: \frac{\partial z_{j}}{\partial \theta_{1}}>0 ; \frac{\partial z_{j}}{\partial \theta_{2}}>0$ if $\frac{\bar{a}_{A B}}{v} \geq 1$, and when $\frac{\bar{a}_{A B}}{v}<1$, [[ $\frac{\partial z_{j}}{\partial \theta_{2}}<0$ if $\theta_{1}<\breve{\theta}$, and $\frac{\partial z_{j}}{\partial \theta_{2}}>$ 0 if $\left.\theta_{1}>\breve{\theta}\right]$, where $\left.\breve{\theta}=\frac{\ln \left(\frac{v}{\bar{a}_{A B}}\right)}{\ln \left(\bar{a}_{A B} v\right)} \in(0,1)\right]$.

(ii) $\quad \lim _{\theta_{1} \rightarrow 0} z_{1}=\left(\frac{\bar{a}_{A B}}{v}\right)^{\theta_{2}}, \lim _{\theta_{2} \rightarrow 0} z_{1}=1, \quad \lim _{\theta_{1} \rightarrow 0} z_{2}=1, \lim _{\theta_{2} \rightarrow 0} z_{2}=\left(\bar{a}_{A B} v\right)^{\theta_{1}}, \lim _{\theta_{1} \rightarrow 1} z_{1}=\bar{a}_{A B} \frac{2 \theta_{2}}{1-\theta_{2}} \lim _{\theta_{1} \rightarrow 1} z_{2}=$ $\bar{a}_{A B} \frac{1+\theta_{2}}{1-\theta_{2}} v, \lim _{\theta_{2} \rightarrow 1} z_{1}=\bar{a}_{A B} \frac{\left(1+\theta_{1}\right)}{1-\theta_{1}} v^{-1}, \lim _{\theta_{2} \rightarrow 1} z_{2}=\bar{a}_{A B} \frac{2 \theta_{1}}{1-\theta_{1}}$.

Proof of Lemma 2. Since, by Assumption 3, $\bar{a}_{A B}>1, v \geq 1$, noting that $\bar{a}_{A B}>1$ implies $\frac{v}{\bar{a}_{A B}}<$ $\bar{a}_{A B} v$, and that, if $\frac{\bar{a}_{A B}}{v}<1, \ln \left(\frac{v}{\bar{a}_{A B}}\right)>0$, part (i) of Lemma 2 follows from (N7)-(N10). Part (ii) follows from (N3)-(N4).

We now continue with the proof of Proposition 2.

(i) In this case, $\frac{\bar{a}_{A B}}{v} \geq 1$; hence, by Assumption 3, $a_{B A, 1} \leq a_{B A, 2} \leq 1$. Since, by Lemma 2(i), for all $j \in\{1,2\}, \quad \frac{\partial z_{j}}{\partial \theta_{1}}, \frac{\partial z_{j}}{\partial \theta_{2}}>0 ; \quad$ and by Lemma 2(ii) $\quad \lim _{\theta_{1} \rightarrow 0} z_{1}=\left(\frac{\bar{a}_{A B}}{v}\right)^{\theta_{2}} \geq 1, \lim _{\theta_{2} \rightarrow 0} z_{1}=1, \quad \lim _{\theta_{1} \rightarrow 0} z_{2}=$ 1, $\lim _{\theta_{2} \rightarrow 0} z_{2}=\left(\bar{a}_{A B} v\right)^{\theta_{1}}>1$, we have $z_{1}, z_{2}>1$. The claim follows from Proposition 1 (parts (ii) and (iii)) and Corollary 1.

(ii) In this case $a_{B A, 1}=\frac{1}{\bar{a}_{A B} v}<1, a_{B A, 2}=\frac{v}{\bar{a}_{A B}}>1$. By Lemma 2(i), $\frac{\partial z_{1}}{\partial \theta_{1}}>0$, and by Lemma 2(ii), $\lim _{\theta_{1} \rightarrow 0} z_{1}=\left(\frac{\bar{a}_{A B}}{v}\right)^{\theta_{2}} \in\left(\frac{\bar{a}_{A B}}{v}, 1\right)$. Now, if $\frac{1}{\bar{a}_{A B} v}>\frac{\bar{a}_{A B}}{v}$, then $\bar{a}_{A B}<1$, a violation of Assumption 3 . Hence, since $\frac{\partial z_{1}}{\partial \theta_{1}}>0, z_{1}>a_{B A, 1}$. Recalling $\frac{\partial z_{1}}{\partial \theta_{1}}>0$, the claim with regard to the impact of an increase in $\theta_{1}$ within territory 1 follows from Proposition 1 (parts (ii) and (iii)) and Corollary 1 . Now notice that, by Lemma 2(i), $\left[\frac{\partial z_{2}}{\partial \theta_{2}}<0\right.$ if $\theta_{1}<\breve{\theta}$, and $\frac{\partial z_{2}}{\partial \theta_{2}}>0$ if $\left.\theta_{1}>\breve{\theta}\right]$, where $\breve{\theta}=\frac{\ln \left(\frac{v}{\bar{a}_{A B}}\right)}{\ln \left(\bar{a}_{A B} v\right)}$; furthermore, by Lemma 2(ii), $\lim _{\theta_{2} \rightarrow 0} z_{2}=\left(\bar{a}_{A B} v\right)^{\theta_{1}}$. Recall that $a_{B A, 2}=\frac{v}{\bar{a}_{A B}}>1$. Suppose $\left(\bar{a}_{A B} v\right)^{\theta_{1}}<\frac{v}{\bar{a}_{A B}}$. Then $\bar{a}_{A B}{ }^{\theta_{1}+1}<v^{1-\theta_{1}}$. Since, by Assumption 3, $\bar{a}_{A B}>1, v>1$, we must therefore have $\theta_{1}<\breve{\theta} \equiv \frac{\ln \left(\frac{v}{\bar{a}_{A B}}\right)}{\ln \left(\bar{a}_{A B} v\right)}$. Thus, [if $\theta_{1}<\breve{\theta}$, then $\lim _{\theta_{2} \rightarrow 0} z_{2}<a_{B A, 2}$ and $\frac{\partial z_{2}}{\partial \theta_{2}}<0$ ] and [if $\theta_{1}>$ 
$\breve{\theta}$, then $\lim _{\theta_{2} \rightarrow 0} z_{2}>a_{B A, 2}$ and $\left.\frac{\partial z_{2}}{\partial \theta_{2}}>0\right]$. Recalling that, by Lemma 2(i), when $a_{A B, 2}<1, \breve{\theta} \in(0,1)$, the claim with regard to the impact of an increase in $\theta_{2}$ within territory 2 follows from Proposition 1 (parts (ii) and (iii)) and Corollary 1.

(iii) In this case $a_{B A, 1}=\frac{1}{\bar{a}_{A B} v}<1, a_{B A, 2}=\frac{v}{\bar{a}_{A B}}>1$. By Lemma 2(i), [ $\frac{\partial z_{1}}{\partial \theta_{2}}<0$ if $\theta_{1}<\breve{\theta}$, and $\frac{\partial z_{1}}{\partial \theta_{2}}>$ 0 if $\left.\theta_{1}>\breve{\theta}\right]$, where $\breve{\theta}=\frac{\ln \left(\frac{v}{\bar{a}_{A B}}\right)}{\ln \left(\bar{a}_{A B} v\right)} \in(0,1)$. Furthermore, by Lemma 2(ii), $\lim _{\theta_{2} \rightarrow 0} z_{1}=1, \lim _{\theta_{2} \rightarrow 1} z_{1}=$ $\bar{a}_{A B} \frac{\left(1+\theta_{1}\right)}{1-\theta_{1}} v^{-1} \in\left(\frac{\bar{a}_{A B}}{v}, \infty\right)$. Now, notice that, by Assumption $3, \frac{\bar{a}_{A B}}{v}>\frac{1}{\bar{a}_{A B} v}$. The claim with regard to the impact of an increase in $\theta_{2}$ within territory 1 follows from Proposition 1 (parts (ii) and (iii)) and Corollary 1. By Lemma 2(i), $\frac{\partial z_{2}}{\partial \theta_{1}}>0$, and by Lemma 2(ii), $\lim _{\theta_{1} \rightarrow 0} z_{2}=1, \lim _{\theta_{1} \rightarrow 1} z_{2}=\bar{a}_{A B}^{\frac{1+\theta_{2}}{1-\theta_{2}}} v \in$ $\left(\bar{a}_{A B} v, \infty\right)$. If $\frac{v}{\bar{a}_{A B}}>\bar{a}_{A B} v$, then $\bar{a}_{A B}<1$, a contradiction. Thus, $\lim _{\theta_{1} \rightarrow 0} z_{2}=1<a_{B A, 2}<\lim _{\theta_{1} \rightarrow 1} z_{2}$, and $\frac{\partial z_{2}}{\partial \theta_{1}}>0$. Now, putting $z_{2}=\bar{a}_{A B} \frac{\theta_{1}\left(1+\theta_{2}\right)}{1-\theta_{1} \theta_{2}} v^{\frac{\left(1-\theta_{2}\right) \theta_{1}}{1-\theta_{1} \theta_{2}}}=\frac{v}{\bar{a}_{A B}}$, we get: $\bar{a}_{A B}{ }^{1+\theta_{1}}=v^{1-\theta_{1}}$, so that $z_{2}<$ (resp. >) $a_{B A, 2}$ if $\theta_{1}<$ (resp. $>$ ) $\breve{\theta}$. Recalling that, by Lemma 2(i), when $a_{A B, 2}<1, \breve{\theta} \in(0,1)$ the claim with regard to the impact of an increase in $\theta_{1}$ within territory 2 follows from Proposition 1 (parts (ii) and (iii)) and Corollary 1.

Proof of Proposition 3. In this case, (N3) and (N4) reduce respectively to:

$$
\begin{aligned}
& z_{1}=\bar{a}_{A B} \frac{\theta w^{-1}+\theta^{2}}{1-\theta^{2}} v \frac{-\left(\theta w^{-1}-\theta^{2}\right)}{1-\theta^{2}} \\
& z_{2}=\bar{a}_{A B} \frac{\theta w+\theta^{2}}{1-\theta^{2}} v \frac{\left(\theta w-\theta^{2}\right)}{1-\theta^{2}} .
\end{aligned}
$$

In turn, (N11) and (N12) yield:

$$
\begin{aligned}
& \ln z_{1}=\left(\frac{\theta w^{-1}+\theta^{2}}{1-\theta^{2}}\right) \ln \bar{a}_{A B}-\frac{\left(\theta w^{-1}-\theta^{2}\right)}{1-\theta^{2}} \ln v, \\
& \ln z_{2}=\left(\frac{\theta w+\theta^{2}}{1-\theta^{2}}\right) \ln \bar{a}_{A B}+\frac{\left(\theta w-\theta^{2}\right)}{1-\theta^{2}} \ln v ;
\end{aligned}
$$

using which we have:

$$
\begin{aligned}
& \frac{1}{z_{1}} \frac{\partial z_{1}}{\partial \theta}=\frac{1}{\left(1-\theta^{2}\right)^{2}}\left[\left[w^{-1}\left(1+\theta^{2}\right)+2 \theta\right] \ln \bar{a}_{A B}-\left[w^{-1}\left(1+\theta^{2}\right)-2 \theta\right] \ln v\right] \\
& \frac{1}{z_{2}} \frac{\partial z_{2}}{\partial \theta}=\frac{1}{\left(1-\theta^{2}\right)^{2}}\left[\left[w\left(1+\theta^{2}\right)+2 \theta\right] \ln \bar{a}_{A B}+\left[w\left(1+\theta^{2}\right)-2 \theta\right] \ln v\right] .
\end{aligned}
$$


$\ln \left(\frac{\bar{a}_{A B}}{v}\right)^{w^{-1}\left(1+\theta^{2}\right)}\left(\bar{a}_{A B} v\right)^{2 \theta}$

Using (N15), we have:

$$
\frac{\partial H}{\partial \theta} \equiv 2\left[\left[\theta w^{-1}+1\right] \ln \bar{a}_{A B}-\left[\theta w^{-1}-1\right] \ln v\right]=2\left[\ln \left(\frac{\bar{a}_{A B}}{v}\right)^{\theta w^{-1}}\left(\bar{a}_{A B} v\right)\right] .
$$

Since $\bar{a}_{A B}>1$, there must exist $\varepsilon_{1} \in(0,1)$ such that $\left(\frac{\bar{a}_{A B}}{v}\right)^{\varepsilon_{1}{ }^{-1}}\left(\bar{a}_{A B} v\right)=1$. Then, since $\left(\frac{\bar{a}_{A B}}{v}\right)<1$, by (N16), for all $w>\varepsilon_{1}, \frac{\partial H}{\partial \theta}>0$. Now, from (N15), $\lim _{\theta \rightarrow 0} H<0$, whereas $\lim _{\theta \rightarrow 1} H=2\left[\left[w^{-1}+\right.\right.$ $\left.1] \ln \bar{a}_{A B}-\left[w^{-1}-1\right] \ln v\right]=2\left[\ln \left(\frac{\bar{a}_{A B}}{v}\right)^{w^{-1}}\left(\bar{a}_{A B} v\right)\right]>0$ for all $w>\varepsilon_{1}$. Hence, recalling (N13), we have:

given any $w>\varepsilon_{1} \in(0,1)$, there exists $\theta^{*} \in(0,1)$ such that $\frac{\partial z_{1}}{\partial \theta}<$ (resp. $>$ ) 0 iff $\theta<$ (resp. $>$ ) $\theta^{*}$.

Recalling that $\left[\bar{a}_{A B}>1, v \geq 1\right]$ by Assumption 3 , and since $a_{A B, 2}<1$ implies $\frac{v}{\bar{a}_{A B}}>1$, yields:

there exists $\varepsilon_{2} \in(0,1)$ such that [if $w>\varepsilon_{2}$, then $\frac{\partial z_{2}}{\partial \theta}>0$ ].

(i) Since $a_{A B, 2}<1, a_{B A, 2}=v \bar{a}_{A B}{ }^{-1}>1$. Now let $\varepsilon=\max \left\{\varepsilon_{1}, \varepsilon_{2}\right\}$, and consider any $w>\varepsilon$. Then, from (N18), $\frac{\partial z_{2}}{\partial \theta}>0$ for all $\theta \in(0,1)$, and the minimum value of $z_{2}$ is 1 . Hence, by parts (ii) and (iii) of Proposition 1, external and total conflict in 2 initially rise in $\theta$, till $z_{2}$ reaches $a_{B A, 2}$, and falls thereafter as $z_{2}$ keeps rising in $\theta$ if the threshold value of $\theta$, at which $z_{2}=a_{B A, 2}$ (so that B's share is the same as that of the low cost combatant $\mathrm{A}$ ) is less than 1 ; internal conflict behaves in the opposite fashion. Using (33), the threshold value of $\theta$, $\hat{\theta}$, is given by $z_{2}=\bar{a}_{A B} \frac{\theta w+\theta^{2}}{1-\theta^{2}} v^{\frac{\left(\theta w-\theta^{2}\right)}{1-\theta^{2}}}=v \bar{a}_{A B}{ }^{-1}$; so that $\bar{a}_{A B}{ }^{(\theta w+1)} v^{(\theta w-1)}=1$, implying $\hat{\theta}=\frac{\ln \left(a_{B A, 2}\right)}{w \ln \left(a_{A B, 1}\right)}=\frac{\vec{\theta}}{w}$. Since $a_{A B, 1}=v \bar{a}_{A B}=\left(a_{B A, 2}\right) \bar{a}_{A B}{ }^{2}$, and $\bar{a}_{A B}>1$, we have $a_{A B, 1}>a_{B A, 2}>1$, so that $\breve{\theta} \in(0,1)$. Since $w>\varepsilon_{1}$, we have $\left(\frac{\bar{a}_{A B}}{v}\right)^{w^{-1}}\left(\bar{a}_{A B} v\right)>$ 1. Then $w>\breve{\theta}$, so that $\hat{\theta} \in(0,1)$. Since $\frac{\partial z_{2}}{\partial \theta}>0$, the claims regarding shares and pay-offs follow from Corollary 1. 
(ii) Let $\varepsilon=\max \left\{\varepsilon_{1}, \varepsilon_{2}\right\}$, and consider any $w>\varepsilon$. Since $a_{A B, 2}<1,1<\bar{a}_{A B}<v$. Since (by Assumption 3) $a_{A B, 1}>1, a_{B A, 1}=v^{-1} \bar{a}_{A B}{ }^{-1}<1$. Thus, recalling (N17), and noting that $\lim _{\theta \rightarrow 0} z_{1}=1$, $z_{1}$ initially falls from with an increase $\theta$ from 0 , reaching its minimum at $\theta=\theta^{*}$, and subsequently rises. Recall that $a_{B A, 1}=v^{-1} \bar{a}_{A B}{ }^{-1}<1$. Suppose $z_{1}\left(\theta^{*}\right) \leq a_{B A, 1}$. Then, using (N11), at $\theta=\theta^{*}$, $\left[\left(\frac{1-\theta w^{-1}}{1-\theta^{2}}\right) \ln v+\left(\frac{\theta w^{-1}+1}{1-\theta^{2}}\right) \ln \bar{a}_{A B} \leq 0\right]$, which implies $w \leq \frac{\ln \left(a_{B A, 2}\right)}{\ln \left(a_{A B, 1}\right)} \theta$, a contradiction, since $w>\varepsilon_{1}$ implies $\left(\frac{\bar{a}_{A B}}{v}\right)^{w^{-1}}\left(\bar{a}_{A B} v\right)>1$, which in turn implies $w>\frac{\ln \left(a_{B A, 2}\right)}{\ln \left(a_{A B, 1}\right)}$. Hence we get:

for all $\theta \in(0,1),\left[z_{1}(\theta)>a_{B A, 1}\right]$.

The claims regarding the effect of an increase in $\theta$ on the behaviour of internal, external and total conflict follow from (N17), (N19) and parts (ii) and (iii) of Proposition 1. Recalling (N17), the claims regarding shares and pay-offs follow from Corollary 1 . At $\theta=\frac{\breve{\theta}}{w}, z_{2}=a_{B A, 2}$, so that $p_{B A, 2}=1$, implying $z_{1}=1$. Recall that, from (N11), $\lim _{\theta \rightarrow 0} z_{1}=1$. In light of (N17), it follows that $\theta^{*}<\frac{\breve{\theta}}{w}$.

(iii) Let $\varepsilon=\max \left\{\varepsilon_{1}, \varepsilon_{2}\right\}$, and consider any $w>\varepsilon$. Then, by (N16), $\frac{\partial H}{\partial \theta}>0$, and, by (N15), $\frac{\partial H}{\partial \bar{a}_{A B}}>$ 0 . Since at $\theta=\theta^{*}, H=0$, it follows that $\frac{\partial \theta^{*}}{\partial \bar{a}_{A B}}<0$. Furthermore, since $\left(\frac{\bar{a}_{A B}}{v}\right)<1, \frac{\partial H}{\partial w}>0$, so that $\frac{\partial \theta^{*}}{\partial w}<0$. Since $\frac{\breve{\theta}}{w}=\frac{\ln \left(\frac{v}{\bar{a}_{A B}}\right)}{w \ln \left(\bar{a}_{A B} v\right)}, \frac{\partial\left(\frac{\breve{\theta}}{w}\right)}{\partial w}, \frac{\partial\left(\frac{\breve{\theta}}{w}\right)}{\partial \bar{a}_{A B}}<0$.

Proof of Proposition 4. We prove Proposition 4 via the following two lemmas.

Lemma 3. Let Assumptions 1-3 hold, and let $\breve{\theta} \equiv \frac{\ln \left(\frac{v}{\bar{a}_{A B}}\right)}{\ln \left(\bar{a}_{A B} v\right)}$.

(i) If $a_{A B, 2} \geq 1$, then, for all $j \in\{A, B\}$, an increase in $a_{A B,-j}$ reduces external and total conflict in territory $j$, while increasing internal conflict within each community in that territory.

(ii) If $a_{A B, 2}<1$, then: (a) provided $\theta_{1} \in(0, \breve{\theta})$, an increase in $a_{A B, 1}$ increases external and total conflict in territory 2 , while reducing internal conflict within each community in that territory; and (b) provided $\theta_{1} \in(\breve{\theta}, 1)$, an increase in $a_{A B, 1}$ reduces external and total conflict in territory 2, while increasing internal conflict within each community in that territory.

(iii) If $a_{A B, 2}<1$, then a decrease in $a_{A B, 2}$ increases external and total conflict in territory 1 , while decreasing internal conflict within each community in that territory.

(iv) For all $j \in\{1,2\}$, the share of community A declines monotonically in territory $j$ as $a_{A B,-j}$ increases, with $\lim _{a_{A B,-j \rightarrow \infty}} p_{A j}=0$; furthermore, the pay-off of $A$ in $j$ declines, and that of $B$ in $j$ rises, monotonically as $a_{A B,-j}$ rises. 
Lemma 4. Let Assumptions 1-3 hold. Then, for all $j \in\{1,2)$ :

(i) $\frac{\partial a_{A B, j}}{\partial l_{A B, j}}>0$; (ii) if $\mu_{B j}>$ (resp. $\left.=\right) \mu_{A j}$, then there exists $\gamma_{j}<$ (resp. $\left.=\right) \frac{1}{2}$ such that $\frac{\partial a_{A B, j}}{\partial n_{j}}<0$ for all $\alpha_{j} \in\left(0, \gamma_{j}\right)$; (iii) if $\mu_{B j}=\mu_{A j}$, then there exists $\rho_{j} \in\left(\frac{1}{2}, 1\right)$ such that, $\left[\frac{\partial a_{A B, j}}{\partial \alpha_{j}}<0\right.$ for all $\alpha_{j} \in$ $\left.\left(0, \rho_{j}\right)\right]$; and (iv) if $\mu_{A}=\mu-e, \mu_{B}=\mu+e$ for some $e \geq 0$, then there exists $\sigma_{j} \in\left[\frac{1}{2}, 1\right)$ such that $\left[\frac{\partial a_{A B, j}}{\partial \mu_{j}}>0\right.$ for all $\left.\alpha_{j} \in\left(0, \sigma_{j}\right)\right]$, with $\sigma_{j}>\frac{1}{2}$ iff $e>0$.

\section{Proof of Lemma 3.}

(i) From (22)-(23), respectively,

$$
\begin{aligned}
& \ln z_{1}=\left(\frac{\theta_{2}}{1-\theta_{1} \theta_{2}}\right) \ln a_{A B, 2}+\left(\frac{\theta_{1} \theta_{2}}{1-\theta_{1} \theta_{2}}\right) \ln a_{A B, 1} ; \\
& \ln z_{2}=\left(\frac{\theta_{1}}{1-\theta_{1} \theta_{2}}\right) \ln a_{A B, 1}+\left(\frac{\theta_{1} \theta_{2}}{1-\theta_{1} \theta_{2}}\right) \ln a_{A B, 2} .
\end{aligned}
$$

Since, by Assumption 3, $a_{A B, 1}>1$, (N20) and (N21) imply: for all $\theta_{1}, \theta_{2} \in(0,1), z_{1}, z_{2}>1$, and $\frac{\partial z_{j}}{\partial a_{A B,-j}}=\left(\frac{\theta_{j}}{1-\theta_{1} \theta_{2}}\right)>0$. Since $a_{A B, 1}, a_{A B, 2} \geq 1$, we have $a_{B A, 1}, a_{B A, 2} \leq 1$. Part (i) of Proposition 4 follows from Proposition 1 (parts (ii) and (iii)) and Corollary 1.

(ii)-(iii) In this case $1<\bar{a}_{A B}<v$, and $a_{B A, 1}=\frac{1}{v \bar{a}_{A B}}<1, a_{B A, 2}=v \bar{a}_{A B}{ }^{-1}>1$. Then, using (N3), $\frac{z_{1}}{a_{B A, 1}}=\bar{a}_{A B} \frac{\left(1+\theta_{2}\right)}{1-\theta_{1} \theta_{2}} v^{\frac{\left(1-\theta_{2}\right)}{1-\theta_{1} \theta_{2}}}$, implying $z_{1}>a_{B A, 1}$. From (N4), $\frac{z_{2}}{a_{B A, 2}}=\left(\frac{\bar{a}_{A B}^{\left(1+\theta_{1}\right)}}{v^{\left(1-\theta_{1}\right)}}\right)^{\frac{1}{1-\theta_{1} \theta_{2}}}$. This ratio is less than 1 at $\theta_{1}=0$, increasing in $\theta_{1}$. It reaches 1 at $\theta_{1}=\breve{\theta} \equiv \frac{\ln \left(v \bar{a}_{A B}{ }^{-1}\right)}{\ln \left(v \bar{a}_{A B}\right)}$ and converges to $\infty$ as $\theta_{1}$ converges to 1 . Hence, $z_{2}<$ (resp. >) $a_{B A, 2}$ if $\theta_{1}<$ (resp. >) $\breve{\theta}$. Recalling that, from (22)-(23), $\frac{\partial z_{j}}{\partial a_{A B,-j}}>0$, parts (ii) and (iii) of Proposition 4 follows from Proposition 1 (parts (ii) and (iii)).

(iv) Recalling that, from (22)-(23), $\left[\frac{\partial z_{j}}{\partial a_{A B,-j}}>0\right]$, and $\lim _{a_{A B,-j \rightarrow \infty}} z_{j}=\infty$, part (iv) of Proposition 4 follows from Corollary 1.

Proof of Lemma 4. In the proof of Lemma 4, we drop the territorial subscript $j$ for notational simplicity.

(i) Part (i) follows immediately from (24).

(ii) From (24),

$$
\left[l_{A B} \frac{(1-\alpha)}{\alpha}\right]^{-1} \frac{\partial a_{A B}}{\partial n} \equiv\left[\frac{\left(1-\mu_{A}\right) \alpha\left[\mu_{B}+\left(1-\mu_{B}\right)(1-\alpha) n\right]-\left(1-\mu_{B}\right)(1-\alpha)\left[\mu_{A}+\left(1-\mu_{A}\right) \alpha n\right]}{\left[\mu_{B}+\left(1-\mu_{B}\right)(1-\alpha) n\right]^{2}}\right] .
$$

Let $\mu_{B}=\mu_{A}+2 \varepsilon$. The numerator on the RHS of (N22) can then be written as:

$$
\begin{aligned}
& Z=\left(1-\mu_{A}\right) \alpha\left[\mu_{A}+2 \varepsilon+\left(1-\mu_{A}-2 \varepsilon\right)(1-\alpha) n\right]-\left(1-\mu_{A}-2 \varepsilon\right)(1-\alpha)\left[\mu_{A}+\left(1-\mu_{A}\right) \alpha n\right] \\
& =\left(1-\mu_{A}\right)(2 \alpha-1) \mu_{A}+2 \varepsilon\left(\alpha-2 \alpha \mu_{A}+\mu_{A}\right) .
\end{aligned}
$$


Now, since $\alpha, \mu_{A} \in(0,1),\left(\alpha-2 \alpha \mu_{A}+\mu_{A}\right)>0$; if $\varepsilon \geq 0, \frac{\partial z}{\partial \alpha}=2\left[\left(1-\mu_{A}-2 \varepsilon\right) \mu_{A}+\varepsilon\right]>0$, since $\mu_{A}+2 \varepsilon=\mu_{B} \in(0,1) . \quad$ At $\alpha=\frac{1}{2},[\mathrm{Z}>0$ if $\varepsilon>0$, and $\mathrm{Z}=0$ if $\varepsilon=0] . \quad$ At $\alpha=0, \quad Z=$ $-\left(1-\mu_{A}-2 \varepsilon\right) \mu_{A}<0$. Hence, given any $\varepsilon \geq 0$, there exists $\rho(\varepsilon) \leq \frac{1}{2}$ such that $\frac{\partial a_{A B}}{\partial n}<0$ for all $\alpha \in$ $(0, \rho(\varepsilon))$., the inequality holding strictly if $\varepsilon>0$.

(iii) From (24),

$$
\frac{1}{l_{A B}} \frac{\partial a_{A B}}{\partial \alpha}=\frac{\left[\mu_{A}+\left(1-\mu_{A}\right) \alpha n\right]}{\left[\mu_{B}+\left(1-\mu_{B}\right)(1-\alpha) n\right]}\left[\frac{-1}{\alpha^{2}}\right]+\frac{\left[\left(1-\mu_{A}\right) n\right]}{\left[\mu_{B}+\left(1-\mu_{B}\right)(1-\alpha) n\right]}+\frac{\left[\mu_{A}+\left(1-\mu_{A}\right) \alpha n\right]\left(1-\mu_{B}\right) n}{\left[\mu_{B}+\left(1-\mu_{B}\right)(1-\alpha) n\right]^{2}} .
$$

Then, assuming $\mu=\mu_{A}=\mu_{B}$, (N23) yields:

$$
\begin{aligned}
\frac{1}{l_{A B}} \frac{\partial a_{A B}}{\partial \alpha} & =\frac{[\mu+(1-\mu) \alpha n][\mu+(1-\mu)(1-\alpha) n]}{[\mu+(1-\mu)(1-\alpha) n]^{2}}\left[\frac{-1}{\alpha^{2}}\right]+\frac{(1-\mu) n[2 \mu+(1-\mu) n]}{[\mu+(1-\mu)(1-\alpha) n]^{2}} \\
& =\frac{(1-\mu) n[2 \mu+(1-\mu) n]-\left[\frac{\mu}{\alpha}+(1-\mu) n\right]\left[\frac{\mu}{\alpha}+(1-\mu)\left(\frac{1-\alpha}{\alpha}\right) n\right]}{[\mu+(1-\mu)(1-\alpha) n]^{2}}
\end{aligned}
$$

The numerator on the RHS of (N24) increases as $\alpha$ increases. At $\alpha=\frac{1}{2}$, the numerator is $d \equiv$ $[2 \mu+(1-\mu) n][-2 \mu]<0$, implying $\frac{\partial a_{A B}}{\partial \alpha}<0$. At $\alpha=1$, the numerator is positive if $\mu$ is sufficiently close to 0 . Part (iii) of Lemma 2 follows by continuity.

(iv) From (24), assuming $\mu_{A}=\mu-e, \mu_{B}=\mu+e$ for some $e \geq 0$,

$$
\left(l_{A B} \frac{(1-\alpha)}{\alpha}\right)^{-1} \frac{\partial a_{A B}}{\partial \mu}=\left[\frac{[1-\alpha n]\left[\mu_{B}+\left(1-\mu_{B}\right)(1-\alpha) n\right]-[1-(1-\alpha) n]\left[\mu_{A}+\left(1-\mu_{A}\right) \alpha n\right]}{\left[\mu_{B}+\left(1-\mu_{B}\right)(1-\alpha) n\right]^{2}}\right] .
$$

The numerator on the RHS of (N25) tends to $\left[\left(\mu_{B}-\mu_{A}\right)\left(1-\frac{n}{2}\right)^{2}\right]$ as $\alpha$ tends to $\frac{1}{2}$; $\left[\left(\mu_{B}-\right.\right.$ $\left.\left.\mu_{A}\right)\left(1-\frac{n}{2}\right)^{2}\right] \geq 0$ if $\mu_{B} \geq \mu_{A}$, with the inequality holding strictly iff $\mu_{B}>\mu_{A}$. Let

$$
q=[1-\alpha n]\left[\mu_{B}+\left(1-\mu_{B}\right)(1-\alpha) n\right]-[1-(1-\alpha) n]\left[\mu_{A}+\left(1-\mu_{A}\right) \alpha n\right] .
$$

Then $\frac{\partial q}{\partial \alpha}<0$. Hence, the numerator in (N25) is positive for all $\alpha \in\left(0, \frac{1}{2}\right)$ if $\mu_{B} \geq \mu_{A}$, and it is positive at $\alpha=\frac{1}{2}$ iff $e>0$. Part (iv) of Lemma 2 follows by continuity.

Proposition 4 follows immediately from Lemmas 3-4. 


\section{References}

Arbatskaya, M., and H.M. Mialon. 2010. "Multi-activity contests." Economic Theory 43: 23-43.

Bakshi, D. and I. Dasgupta. 2015. "A model of dynamic conflict in ethnocracies.” Defence and Peace Economics (forthcoming), DOI: 10.1080/10242694.2015.1092204.

Barbieri, K. and R. Reuveny. 2005. "Economic globalization and civil war", Journal of Politics 67(4): 1228-1247.

Brett, M. 1988. "Legislating for Inequality in Algeria". Bulletin of the School of Oriental and African Studies 51 (3): 440-461.

Callander, S. 2007. "Bandwagons and momentum in sequential voting." Review of Economic Studies 74: 653-684.

Caselli, F. and W. Coleman. 2013. "On the theory of ethnic conflict." Journal of the European Economic Association 11 (S1): 161-192.

Choi, J.P., S.M Chowdhury and J. Kim. 2015. "Group contests with internal conflict and power asymmetry." Scandinavian Journal of Economics (forthcoming), DOI: 10.1111/sjoe.12152.

Chrisafis, A. 2015. "Front National wins opening round in France's regional elections", The Guardian, 7th December 2015; http://www.theguardian.com/world/2015/dec/06/frontnational-wins-opening-round-in-frances-regional-elections.

Collier, P. and A. Hoeffler. 2004. "Greed and grievance in civil wars." Oxford Economic Papers 56: 563-95.

Dal Bo', E. and P'. Dal Bo. 2011. "Workers, warriors and criminals: social conflict in general equilibrium.” Journal of the European Economic Association 9 (4): 646-677.

Dasgupta, I. 2009. “'Living' wage, class conflict and ethnic strife.” Journal of Economic Behavior and Organization 72 (2): 750-765.

Dasgupta, I. and R. Kanbur. 2011. “Does philanthropy reduce inequality?” Journal of Economic Inequality 9 (1): 1-21.

Dasgupta, I. and R. Kanbur. 2007. “Community and class antagonism.” Journal of Public Economics 91 (9): 1816-1842.

Dasgupta, I. and R. Kanbur. 2005a. "Community and anti-poverty targeting." Journal of Economic Inequality 3 (3): 281-302. 
Dasgupta, I. and R. Kanbur. 2005b. "Bridging communal divides: separation, patronage, integration.” In The Social Economics of Poverty: On Identities, Groups, Communities and Networks, edited by C. Barrett, 146-170. London: Routledge.

Dechenaux, E., D. Kovenock and R.M. Sheremeta. 2014. "A survey of experimental research on contests, all-pay auctions and tournaments." Experimental Economics. Advance online publication. doi: 10.1007/s10683-014-9421-0.

Davidson, J. S. 2008. From Rebellion to Riots: Collective Violence in Indonesian Borneo. Madison: University of Wisconsin Press.

Easterly, W. 2001. “Can institutions resolve ethnic conflict?” Economic Development and Cultural Change 49(4): 687-706.

Easterly, W., R. Gatti and S. Kurlat. 2006. "Development, democracy and mass killings." Journal of Economic Growth 11(2): 129-56.

Esteban, J. and D. Ray. 2011. “A model of ethnic conflict”, Journal of the European Economic Association 9(3): 496-521.

Esteban, J. and D. Ray. 2008. “On the salience of ethnic conflict”, American Economic Review 98: 2185-2202.

Ferguson, N. 2006. The War of the World: Twentieth-Century Conflict and the Descent of the West. New York: Penguin.

Gleditsch, K.S. 20007. “Transnational dimensions of civil war.” Journal of Peace Research 44: 293-309.

Hoeffler, A. 2012. "On the causes of civil war." In The Oxford Handbook of the Economics of Peace and Conflict, edited by M. Garfinkel and S. Skaperdas, 179-204. Oxford: Oxford University Press.

Katz, E., S. Nitzan, and J. Rosenberg. 1990. "Rent-seeking with pure public goods." Public Choice 65 (1): 49-60.

Kolmar, M. and H. Rommeswinkel. 2013. “Contests with group-specific public goods and complementarities in efforts.” Journal of Economic Behavior and Organization 89: 9-22.

Kovenock, D. and B. Roberson. 2012. "Conflicts with multiple battlefields." In The Oxford Handbook of the Economics of Peace and Conflict, edited by M. Garfinkel and S. Skaperdas, 503-531. Oxford: Oxford University Press.

Magee, C. and T. Massoud. 2011. "Openness and internal conflict", Journal of Peace Research 48(1): 59-72. 
Montalvo, J. and M. Reynal-Querol. 2008. "Discrete polarization with an application to the determinants of genocides", Economic Journal 118(533): 1835-65.

Montalvo, J. and M. Reynal-Querol. 2005. "Ethnic polarization, potential conflict and civil wars", American Economic Review 95(3): 796-816.

Münster, J. 2007. "Simultaneous inter- and intra-group conflicts." Economic Theory 32: 333-352.

Riaz, A. 2008. Islamist Militancy in Bangladesh: A Complex Web. London: Routledge.

Tullock, G. 1980. "Efficient rent seeking." In Toward a Theory of the Rent-seeking Society, edited by J.M. Buchanan, R.D. Tollison, and G. Tullock, 97-112. College Station: Texas A and M University Press.

Varshney, A. 2002. Ethnic Conflict and Civic Life: Hindus and Muslims in India. New Haven: Yale University Press.

Varshney, A. 2008. "Collective violence in Indonesia: an overview." The Journal of East Asian Studies 8(3): 341-360.

van Klinken, G. 2007. Communal Violence and Democratization in Indonesia. London: Routledge.

Wilkinson, S. I. 2005. Votes and Violence: Electoral Competition and Ethnic Riots in India. Cambridge: Cambridge University Press.

\section{Figure 1}

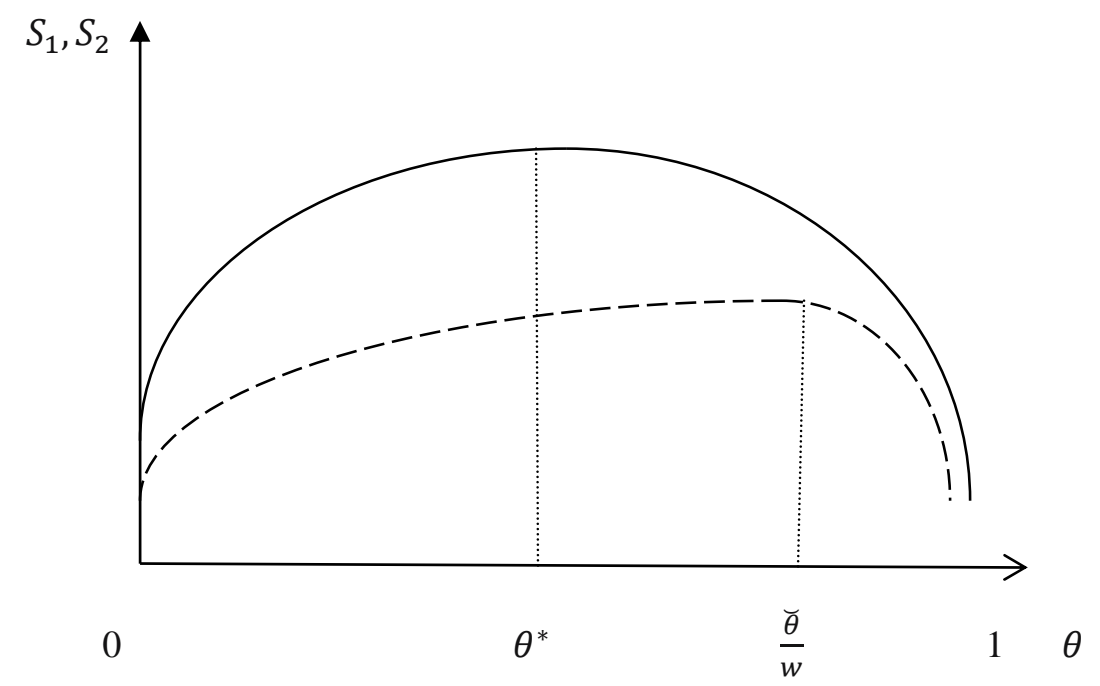


Figure 2

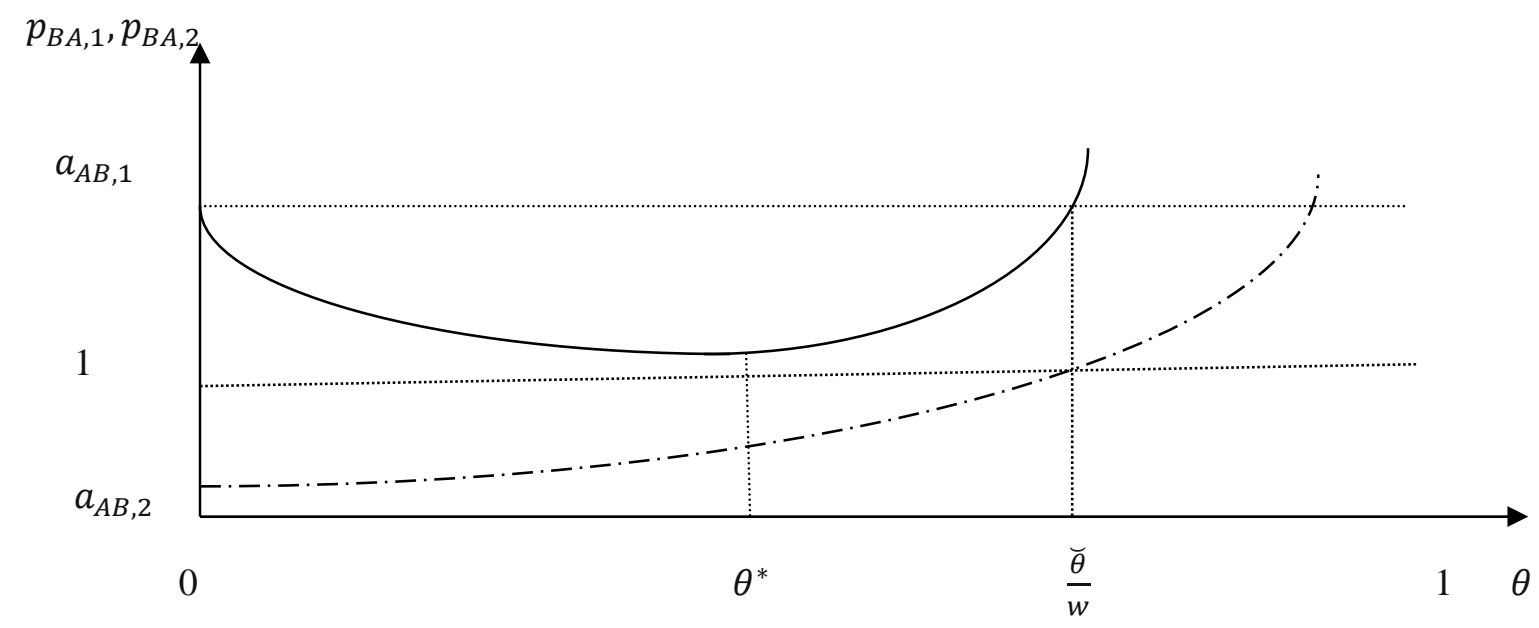

